Canadian

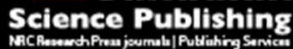

Canadian Geotechnical Journal Revue canadienne de géotechnique

\title{
An equation to predict maximum pipe stress incorporating internal and external loadings on buried pipes
}

\begin{tabular}{|r|l|}
\hline Journal: & Canadian Geotechnical Journal \\
\hline Manuscript ID & cgj-2015-0500.R1 \\
\hline Manuscript Type: & Article \\
\hline Date Submitted by the Author: & 08-Jan-2016 \\
\hline Complete List of Authors: & $\begin{array}{l}\text { Robert, Dilan; RMIT University, Civil, Environmental and Chemical } \\
\text { Rajeev, Pathmanathan; Swinburne University of Technology, Civil and } \\
\text { Construction Engineering } \\
\text { Kodikara, Jayantha; Monash University, } \\
\text { Rajani, Balvant; Principal Engineer, Rajani Consultants Inc, }\end{array}$ \\
\hline Keyword: & $\begin{array}{l}\text { Buried pipes, failure prediction, stress analysis, analytical models, traffic } \\
\text { loads, internal water pressure, pipe corrosion }\end{array}$ \\
\hline & \\
\hline
\end{tabular}

SCHOLARONE ${ }^{\mathrm{m}}$

Manuscripts 


\title{
An equation to predict maximum pipe stress incorporating internal and external loadings on buried pipes
}

\author{
D.J. Robert ${ }^{1}$, P. Rajeev ${ }^{2}$, J. Kodikara ${ }^{3}$ and B.Rajani ${ }^{4}$ \\ ${ }^{1}$ Lecturer in Civil Engineering, School of Engineering, Civil Engineering Department, RMIT \\ University, VIC 3001, Australia, Tel: +61 (0) 39925 1908, email: dilan.robert@,rmit.edu.au \\ (Formerly at Monash University) \\ ${ }^{2}$ Senior Lecturer in Civil Engineering, Department of Civil and Construction Engineering, Swinburne \\ University of Technology, VIC 3122, Tel: +61 (0) 3 92144942, Australia, email: \\ prajeev@swin.edu.au (Formerly at Monash University) \\ ${ }^{3}$ Professor of Civil Engineering, Department of Civil Engineering, Monash University 3800, \\ Melbourne, VIC 3800, Australia, Tel: +61 (0) 3990 54963, email: Jayantha.Kodikara@monash.edu \\ ${ }^{4}$ Principal Engineer, Rajani Consultants Inc, email: balvant.rajani@gmail.com \\ *Correspondence, E-mail: jayantha.kodikara@monash.edu
}

\begin{abstract}
Pipelines used for water and other services are very important lifelines in modern society. Commonly, these buried pipes are subjected to significant stresses due to external (traffic and earth) and internal (water pressure) loads. As many of these pipelines were laid some time in the last century or earlier, in most cases their condition has deteriorated primarily by electro-chemical and/or micro-biological corrosion. Corrosion activity (internal and external) can manifest in various forms, but in many cases will lead to reduced pipe thickness, which in turn leads to an increase in pipe stresses induced by the external and internal loads. Currently available analytical procedures to estimate pipe stresses are based on over-simplifications such as the two dimensional (2-D) analysis based on Winkler springs, limiting their application to general pipe burial conditions. This paper describes the application of a 3D finite element method to analyse a buried pipe subject to external and internal loads. Firstly, the
\end{abstract}


finite element model is validated against the data from field tests conducted on the basis of a cast iron pipe which was laid in 1930 at Strathfield, Sydney. The results of these 3-D finite element analyses are then used to develop a closed-form expression to predict maximum stresses in pipes of different sizes buried in different soil types. Having obtained a good agreement between the proposed model outcomes and the 3-D FE results, the proposed model has been validated against the field test data under different internal and external loadings. The verified outcomes of the model reveal that it can be used to predict maximum stresses without conducting full-scale finite element analysis, which often requires specific computational resources and computational skills. Further, the proposed model can be used in probabilistic analyses, where a large number of calculations need to be carried out to account for the uncertainty of the input variables. The applications of the model are also discussed in relation to the assessment of pipe performance and remaining safe life.

Keywords: Buried Pipes, Failure Prediction, Stress Analysis, Analytical Models, Traffic Loads, Internal Water Pressure, Pipe Corrosion, Field Tests 


\section{Introduction}

Pipelines used for water and other services are very important lifelines in modern society. Commonly, these buried pipes are subjected to significant stresses due to external (traffic and earth) and internal (water pressure) loads. As many of these pipelines were laid some time in the last century or earlier, in most cases, their condition has deteriorated, primarily by electro-chemical and/or micro-biological corrosion. Corrosion activity (internal and external) can manifest in various forms, but generally leads to reductions in pipe thickness. The reduction in pipe thickness in turn leads to increased pipe stresses due to external and internal loads. Consequently, pipe bursts have become common and the management of these pipelines, in particular the critical large diameter pipelines, has become a pressing issue for water authorities worldwide. In contrast to the design of a new pipeline, the main questions here are the determination of how close a critical pipeline is to failure and the remaining life of the pipeline. In this regard, it is necessary to use models that take into account the internal and external factors that contribute to pipe stresses as accurately as possible.

Current practice in estimating pipe stresses is to use analytical and semi-empirical solutions such as those developed by Spangler (1941) and Watkins and Anderson (1999). Although these solutions are widely used in practice, the solutions involve various assumptions and limitations. For instance, threedimensional effects are ignored and the use of Winkler springs to analyse pipe-soil interaction is a limitation. A more advanced approach is to solve the problem using 3-D finite element analyses to determine the stress distribution for a pipe at hand with a specific set of both external and internal factors. Unfortunately, this process can be very time-consuming and requires specialised skills and resources in the computer analysis of soil/structure interactions. In the present paper, 3-D finite element analyses are used to undertake extensive parametric studies to compute stresses generated in buried rigid pipe. Firstly, the finite element model is validated against the data from field tests conducted on the basis of a cast iron pipe which was laid in 1930 at Strathfield, Sydney. The results of the validated 3-D finite element model are used to develop a closed-form solution using nondimensional analysis, paying due consideration to the most relevant internal and external factors. The 
solution is presented in a form suitable for pipe stress analysis that facilitates failure prediction or remaining life estimation.

\section{Current Pipe Stress Analysis}

Pipes are typically designed as rigid or flexible, although this demarcation is approximate and all pipes experience behaviour specific to these two categories to a different degree (Young and Trott 1984). For instance, a rigid pipe made of cast iron may become flexible if the pipe thickness reduces appreciably. In this regard, the discussion below and the following development of a new equation consider pipes generally, incorporating the general mechanics of the pipe-soil interaction.

In common terminology, rigid pipes include pipes made from stiff brittle materials such as reinforced concrete, vitrified clay and cast iron, while flexible pipes include pipes made from less stiff ductile materials such as steel, fibre-glass and high density polyethylene. Rigid pipes are sufficiently strong (both within the pipe wall and joints) to withstand most anticipated external (traffic and earth) and internal (water pressure) loads without the contribution of horizontal soil support, which is assumed to be negligible in the design of rigid pipes. Therefore, the design of rigid pipes is mainly governed by the ultimate yield strength or fracture toughness of the pipe material. In contrast, flexible pipes rely upon the deformation of the pipe from imposed loads to mobilise the support of embedment materials on both sides of the pipe. The primary structural function is distributing the imposed vertical loads to the surrounding soil. In general, flexible pipe can deflect more than $2 \%$ without cracking. Only a small portion of the imposed load is actually carried by the flexible pipe itself, while the majority is transferred to the surrounding bedding material. Therefore, the design of flexible pipes relies on the soil restraint developed as a result of the pipe deflection caused by the imposed loads. Therefore, the design of flexible pipes is mainly controlled by either deflection or elastic buckling.

Two keys aspects of the analysis of a buried pipe are the consideration of external and internal loads acting on the pipe and the determination of critical stresses and deformations (in the case of flexible pipes) that the pipe experiences with respect to these loads.

\subsection{Pipe stress due to external and internal loads}


The determination of pipe stress due to external and internal loading is important for the design of new pipes and the assessment of an existing pipe. The structural design of buried pipe is based on various criteria, such as (1) internal pressure, which may cause bursting; (2) corrosion and erosion, which may reduce wall thickness; (3) crippling of the pipe wall or seams caused by external soil pressure (this may be crushing or buckling of the wall); and (4) ring deflection or change in diameter (flattening down) of the ring due to compression of the soil and traffic load (Watkins and Smith 1967).

Ring deflection can be ignored for a rigid pipe under soil and traffic load. Therefore, the pipe stress can be computed using the elastic ring theory with an assumed soil stress distribution around the pipe to mimic the effects of soil-structure interaction. Two different soil stress distributions are typically assumed in rigid pipe design: (1) uniform vertical stress due to backfill and traffic load is assumed at the pipe crown level and the invert level and no lateral support from the adjacent soil; (2) uniform vertical stress due to soil and traffic load is assumed at the pipe crown level and the invert level and uniform lateral stress at the sides. The lateral stress is calculated using the lateral earth pressure coefficient. Figure 1 shows the assumed pressure distributions around a rigid pipe.

On the basis of the assumed pressure distribution shown in Fig. 1(a) (i.e., no lateral support), the maximum bending stress in the pipe can be computed using the elastic ring theory, as given by Watkins and Anderson (2000):

$$
\sigma_{\max }=\frac{1.5 \cdot q \cdot D^{2}}{4 \cdot t^{2}}
$$

where, $q$ is the uniform vertical stress due to soil and traffic loads, $D$ is the mean pipe diameter and $t$ is the pipe wall thickness.

For the assumed pressure distribution shown in Fig. 1(b) (i.e., with lateral support), the maximum bending stress in the pipe can also be computed using the elastic ring theory (Watkins and Anderson 1999) as follows: 


$$
\sigma_{\max }=\frac{k \cdot q \cdot D}{2 \cdot t}+1.5 \cdot(1-k) \frac{q \cdot D^{2}}{4 \cdot t^{2}}
$$

where, $q$ is the uniform vertical stress due to soil and traffic loads and $k$ is the lateral earth pressure coefficient. In both the above calculations, stress $q$ is required to be estimated using a suitable method.

The deflection of the ring is often the most important consideration in flexible pipe design and it requires the accurate determination of stresses around the pipe due to soil and traffic loads. The Spangler stress formula and the modified Iowa formula are typically used in the design of buried flexible pipes. The Spangler stress formula computes the circumferential bending stress at the pipe invert due to vertical load as follows (e.g., Masada 2000):

$$
\sigma=\frac{3 \cdot K_{b} \cdot W_{\text {vertical }} \cdot E \cdot t \cdot D}{E \cdot t^{3}+8 \cdot K_{z} \cdot p \cdot D^{3}}
$$

where $W_{\text {vertical }}$ is the vertical load due to backfill and surface loads including an impact factor, $E$ is the pipe modulus of elasticity and $P$ is the internal pressure. $K_{b}$ and $K_{z}$ are bending moment and deflection parameters, respectively, that depend on the bedding angle. The appropriate values of $K_{b}$ and $K_{z}$ can be found in Moser and Folkman (2008).

In 1941, Spangler combined the elastic ring theory and his unique "fill-load hypothesis" to establish the original Iowa formula to estimate pipe ovality due to vertical loads. The fill-load hypothesis comprises three elements: (1) The vertical load on a pipe may be determined by Marston's theory and is distributed approximately uniformly over the crown pipe width; (2) The vertical reaction on the bottom of a pipe is equal to the vertical load on the pipe and is distributed approximately uniformly over the invert pipe width; (3) The passive horizontal pressure on the side of the pipe is distributed in a parabolic shape over the middle $100^{\circ}$ of the pipe and the maximum unit pressure is equal to the modulus of passive pressure of the side fill material multiplied by one-half of the horizontal deflection of the pipe. The assumed stress distribution around a flexible pipe is shown in Fig. 2, as given in Masada (2000). 
Based on the assumed stress distribution, the Iowa formula was derived as follows:

$$
\Delta x=\frac{D_{L} W_{v e r t i c a l} r^{3} K_{z}}{E I+0.061 E^{\prime} r^{3}}
$$

where $\Delta x$ is the horizontal diameter change, $D_{L}$ is the time lag factor, $I$ is the moment of inertia of pipe wall section, $r$ is the radius of the pipe, and $E^{\prime}$ is the modulus of passive soil resistance. The time lag factor $D_{L}$ was introduced to recognize a slight increase in pipe deflections over time due to consolidation of the soil at the sides of the pipe. The values for $D_{L}, K_{b}$ and $K_{z}$ can be found elsewhere (Masada 2000).

The original Spangler formula given in Eq. 3 does not include the beneficial effects of lateral soil restraint. By combining the original Spangler formula and the Iowa formula, Warman et al. (2009) proposed the modified Spangler equation as follows:

$$
\sigma=\frac{6 \cdot K_{b} \cdot W_{\text {vertical }} \cdot E \cdot t \cdot r}{E \cdot t^{3}+24 \cdot K_{z} \cdot p \cdot r^{3}+0.732 \cdot E^{\prime} \cdot r^{3}}
$$

For the design of the pipe, the operating/working pressure $\left(p_{W}\right)$ and the surge pressure $\left(p_{S}\right)$ are added to find the design pressure. The stress due to internal pressure can be computed using Barlow's hoop tension formula as follows:

$$
\sigma_{p}=\frac{\left(p_{W}+p_{S}\right) \cdot r}{t}
$$

As stated above, the accuracy of prediction of pipe stress depends on the accurate determination of the external and internal loads exerted on the pipe. The calculation of maximum stress for the design of pipes subjected to external loading suffers from a number of uncertainties: (1) most of the design methods use the Boussinesq theory to estimate the traffic load experienced by the pipe, assuming that the loaded soil mass is homogeneous and ignoring the presence of a stiff pipe within the soil; (2) the Spangler stress formula and the Iowa formula have somewhat inconsistent treatment of the internal pressure stiffening and soil resistance effects; (3) stress equations are based on assumed and 
approximate soil stress distributions around the pipe; (4) the variations of soil density that can occur in the various zones during pipe installation are not considered; (5) the demarcation of rigid and flexible pipes is somewhat arbitrary, and all pipes experience stress distribution governed by the same mechanics but with varying degrees of relevance; and (5) any possible slip between the pipe and the surrounding soil is not considered. A more complete stress analysis using finite element method may be able to reduce some of these limitations.

\subsection{Failure Prediction}

The current state of a buried pipe is normally assessed using the framework by Schlick (1940), where the pipe stress can be represented as interaction curves combining the external and internal variables, namely, the internal pressure and the external traffic load. The Schlick interaction curve is developed on the basis of the experimental load tests conducted on cast iron pipe subjected to combined internal pressure and uniform external three-edge loading along its length. The failure of a pipe section occurs when the following criterion is satisfied:

$$
\frac{P}{P_{c}}+\left(\frac{W}{W_{c}}\right)^{2}>1
$$

where, $P$ is the internal pressure (i.e., $\left.p_{W}+p_{S}\right), P_{c}$ is the critical pressure that would cause failure in the absence of any external loading, $w$ is the applied external load (i.e., $W_{\text {vertical }}$ ) and $W_{c}$ is the external load that would cause failure with no internal pressure. Although Schlick's experimental work was originally conducted on cast iron water and gas pipes, the criterion in Equation 7 is used generally to design against failure in all rigid pipeline materials (Watkins and Anderson 1999).

\section{Basis for a New Pipe Stress Prediction Equation}

In this section, the basis for the development of a new and improved equation, particularly for the evaluation of maximum stress in existing buried pipes, is considered. A finite element model has been developed to compute the pipe stress due to traffic and pressure loads. A detailed description of the finite element model and loadings is given below. 


\subsection{Finite Element Model Description}

Three-dimensional (3-D) finite element analyses were carried out using ABAQUS 6.11/standard to obtain the pipe and soil stress distribution around the pipe that were used to develop the pipe stress prediction model. The soil was represented by 8 -noded brick reduced integration elements and the pipe was represented by 8 -noded shell reduced integration elements. The behaviour of both soil and pipe were assumed to be linear elastic, similar to what is assumed in the derivation of the available analytical solutions. i.e., soil is assumed to be over-consolidated and behave elastically during the range of tested traffic loads (the effects of soil plasticity studied using non-linear plasticity soil models are reported in Section 3.3). The soil side boundaries of the FE model were assumed to be smooth and located far (i.e., $5 \mathrm{~m}$ ) from the pipe ( $\&$ traffic loads) to eliminate any boundary effects. Figure 3 shows the mesh discretization $(6,600$ shell elements and 108, 000 solid elements to represent the pipe and soil, respectively) and model dimensions. The appropriate dimensions and the mesh density of the model were selected after a number of trials to minimise mesh and boundary effects on the calculated pipeline stresses.

Based on the variations considered in the physical variables in Table 1, 830 3-D analyses were conducted. In the following sections, the FE model is first validated against the data from field experiments. Secondly, the numerical results are compared with the analytical models (i.e., the Spangler model) in terms of soil and pipe stresses. Then, the numerical results are used to generate a closed-form non-linear regression equation for pipe maximum tensile stress under operating conditions of the pipe and internal/external loading conditions.

\subsection{Validation of the FE model using field test data}

The developed 3-D FE model was first validated using field experiments, which were conducted as a part of an advanced condition assessment and pipe failure prediction project. A series of field tests was conducted to investigate the behaviour of cast iron pipe under traffic loading. A decommissioned $660 \mathrm{~mm}$ diameter spun cast iron pipe (25mm thickness), which was laid in 1930 at Strathfield, Sydney was selected for the investigations. The pipe and surrounding soil were instrumented with strain 
gauges and pressure pads to monitor the behaviour of the system during the applications of truck loads and water pressure loading. Fig. 4 shows the instrumentation of the pipe used in the field test. The pipe was instrumented by excavating pits to the required depth to expose the pipe (burial depths were from $700 \mathrm{~mm}$ to $1080 \mathrm{~mm}$ at the edge and middle of the road respectively). In addition to monitoring the pipe deformations, the response of soil was also recorded for in situ/traffic loadinduced ground pressures, moisture and temperature variations. Initially, the field tests were conducted on the road base using different trucks moving at various speeds (stationary, $5 \mathrm{kmph} \& 15$ $\mathrm{kmph})$. The pipe response was secondly measured while pressurizing the water $(0-700 \mathrm{kPa})$ in the pipe with the trucks being stopped and driven on the final asphalt road. A complete description of the field test, including instrumentation and preparation, is presented in Chan et al. (2015).

A 3-D finite element model was developed in ABAQUS to simulate the field tests. The properties of the pipe and soil used in the analysis are shown in Table 2. The cast iron and subgrade material properties were obtained from laboratory experiments conducted at Monash University, i.e., the stiffness of the cast iron was obtained using tensile tests conducted on coupons cut from the field test pipe. The stiffness of the subgrade material was obtained from triaxial tests (consolidated undrained) conducted on samples dug out from the field test bed (Fig. 5). Other properties were assumed as given in the relevant standards (Austroads 2010). The behaviour of both pipe and soil were assumed to follow elastic behaviour.

Firstly, the results of the test conducted using a small truck [single axle single tyre (SAST) axle load 4.85t] placed on the road base was used to validate the 3-D FE model for traffic loading on the road base. The results were compared with field data for pipe deformation (i.e. strains $\&$ stresses) and soil stresses. It can be seen that the FE model predicts similar strain distributions and amounts to those observed by the strain gauges (Fig. 6(a)). This is also reflected in the circumferential stress comparison between the FE model and the field pipe (Fig. 6(b)). The maximum difference of the strains between the field data and FE prediction is less than $10 \%$. 
The soil stresses above the pipe level between the FE model and field soil also show similar distributions and amounts (maximum difference $<5 \%$ ), reflecting reliable FE model predictions (Fig. 7). The initial over-burden stress of $\sim 14 \mathrm{kPa}$ at the pipe level was increased to $\sim 38 \mathrm{kPa}$ due to the truck loading. However, such levels of stress increase imply only soil elastic deformations under very high initial stiffness (100MPa for base and 8MPa for subgrade). Therefore, the assumption used in the FE model to idealise the soil behaviour as elastic is justified.

Analyses were also conducted to simulate the simultaneous pressure loadings and traffic loadings on the buried pipe. The tested water pressure was varied from $0-700 \mathrm{kPa}$ and the traffic loads were changed by the truck loads. The results of the test conducted on the basis of a medium-sized truck (SAST axle load 5.78t) placed on the final road were used to validate the 3-D FE model under both pressure and traffic loading. First, the FE results were compared with the field data for water pressure loading excluding traffic loads to investigate the model's capability to capture the water pressure loading. In this regard, the FE-predicted circumferential strains are compared to field-observed data in Fig. 8 at four stages of pressurizing the pipe; $200 \mathrm{kPa}, 350 \mathrm{kPa}, 550 \mathrm{kPa}$ and $690 \mathrm{kPa}$. It can be seen that the FE model predictions of strain distribution and amounts are consistent with the field data at different water pressure loadings. Second, the FE results were compared with the field data for the scenarios of both the water pressure loading and traffic loading conditions. Similar to the pressure loading scenario, the FE models predict realistic strain distributions and amounts when compared with the field-observed data for traffic loading on the pressurised pipe (Fig. 9(a)). A comparison of circumferential stress between the FE model and the values obtained from field data also shows good agreement (Fig. 9(b)). Therefore, it is considered that the 3-D FE model used to predict the buried pipe response under internal and external loading captures the essential mechanics of the field problem.

\subsection{Soil plasticity effect on buried water pipes}

Analyses were performed using the conventional Mohr-Coulomb model to investigate the effect of soil plasticity on buried pipeline subjected to internal and external loads. Simulations were 
conducted on the basis of a buried pipeline [cover height $(\mathrm{H})$ / diameter (D) - 1.3] with a diameter and thickness of $660 \mathrm{~mm}$ and $15 \mathrm{~mm}$ respectively. The pipeline was assumed to operate at $600 \mathrm{kPa}$ water pressure and under varying traffic loads (i.e. tyre loads) ranging from $0-30 \mathrm{kPa}$ (SAST configuration).

The soil condition was simulated on the basis of subgrade soil properties derived from the field testbed samples. Saturated consolidated undrained triaxial tests were conducted on these samples at confining stresses of $10 \mathrm{kPa}, 30 \mathrm{kPa}$ and $50 \mathrm{kPa}$. Based on laboratory test data (Fig. 5), the soil properties (effective stress-based) were obtained as $8 \mathrm{MPa}, 32.2^{\circ}$ and $8 \mathrm{kPa}$ for stiffness, friction angle and cohesion respectively. The simulations were conducted at the same initial density $\left(18.5 \mathrm{kN} / \mathrm{m}^{3}\right)$ observed in the test-bed.

The results of the elasto-plastic analysis were compared with the corresponding analysis simulating elastic soil response. The results show that the maximum pipe circumferential stresses during pressure loading (i.e. only water pressure) are identical for elastic and elasto-plastic analysis (Fig.10). This response can be explained by the soil stress distribution at the top of the pipe being consistent between the analyses. The results also reveal that the pipe maximum stress during traffic loading can be similar for both the soil idealizations under small traffic loads $(<20 \mathrm{kN})$, as shown in Fig. 11. For higher traffic loads $(30 \mathrm{kN}$ representing a large truck load), there is less than $5 \%$ difference in the maximum pipe stress among the different soil modelling scenarios, i.e., the maximum pipe stresses at $30 \mathrm{kN}$ traffic loading are $22 \mathrm{MPa}$ and $21 \mathrm{MPa}$ for pipes buried in elastic and elasto-plastic soil respectively. The response during traffic loading can be explained using the elementary evolutions of the stress paths in the $\pi$-plane (in the direction of the isotropic axis) at the ground surface and at the pipe level at traffic loads of $0 \mathrm{kPa}, 10 \mathrm{kPa}, 20 \mathrm{kPa}$ and $30 \mathrm{kPa}$. As shown in Fig. 12, the deviatoric stress in soil at the pipe level is hardly affected by the traffic loads, in contrast to the stresses near the ground surface, i.e., the deviatoric stress in the soil at the pipe level changes from $21.2 \mathrm{kPa}$ to $22.1 \mathrm{kPa}$ when the traffic load changes from $0 \mathrm{kPa}$ to $30 \mathrm{kPa}$. Hence, the small difference of pipe maximum stress calculated considering either the elastic or the elasto-plastic soil can be attributed to the limited increase in the soil mean pressure at the pipe level during traffic loading. 
Considering the small difference in pipe stress prediction $(<5 \%)$ between elastic and Mohr-Coulomb soil plasticity, and the significant computation time required for Mohr-Coulomb plasticity [identical 3-D simulations using intel 12 cores $2.67 \mathrm{GHz}-128 \mathrm{~GB}$ RAM consumed 3 hours and 12 hours for elastic and Mohr-Coulomb analyses respectively], the analyses for the parametric study utilized linear elastic soil response. The linear elasticity assumption used to simulate the soil behaviour can also be justified using the comparable soil stress predictions between the FE model and actual observations in the field (Fig. 7).

\subsection{Effect of soil-pipeline interaction}

A series of FE analyses were conducted to investigate the effect of interface friction between pipe and soil. A pipeline (diameter $660 \mathrm{~mm}$ and thickness $15 \mathrm{~mm}$ ) buried at $1.2 \mathrm{~m}$ depth and operating at $0.6 \mathrm{MPa}$ water pressure was tested for a range of traffic loadings. The interaction between the pipe and soil was modelled on the basis of the Coulomb friction model which relates the maximum allowable frictional shear stress $\left(\tau_{c r i t}\right)$ across the interface to the contact pressure $\left(\sigma_{n}^{\prime}\right)$ between the pipe and soil. The allowable frictional stress is given by $\mu \sigma_{n}^{\prime}$ where $\left(\tan \phi_{\mu}\right)$ is the interface friction coefficient. The contacting surfaces will stick together and the behaviour remains elastic when $\tau<\tau_{\text {crit }}$. The slipping along the interface between the buried pipe and surrounding soil takes place once $\tau$ produced in the interface reaches $\tau_{c r i t}$. This behaviour was modelled using the finite movement solution available in ABAQUS (ABAQUS, 2011).

The results of the analyses are shown in Fig. 13 for maximum circumferential stress of the pipe under various traffic loading for different interface conditions. They reveal that the interface friction has a negligible effect on the resulting pipe maximum stress. However, Potyondy (1961) showed that skin friction between soil and construction material (such as steel and concrete) can be substantial and depends on many factors such as the moisture content of soil, roughness of surface, composition of soil and the intensity of normal loads. Considering the negligible effect of the pipe-soil interface in 
this problem, the analyses conducted in this study assume a frictionless interface, as was assumed in developing the analytical models available for pipe stress predictions.

\subsection{Evaluation of traffic load}

Since traffic load has been identified as a key variable contributing to pipe stress, initially, a more detailed treatment was given to examine how traffic load may be presented in a simplified form from a plethora of axle and load configurations coming from a typical traffic spectrum applicable to a paved road. Table 3 shows typical axle configurations and ranges of axle loads measured at a weighin-motion (WIM) system on a highway in Victoria, Australia. One of the questions that needs to be examined is whether we could utilise a single representative load on the surface to represent multiple axle configurations and tyre loads. This is briefly examined using FE analysis of a typical pavement system.

A pavement system consisting of a top asphalt layer (thickness $=240 \mathrm{~mm}$, modulus $=3 \mathrm{GPa}$ ), unbound base layer (thickness $=100 \mathrm{~mm}$, and modulus $=300 \mathrm{MPa}$ ), and subgrade soil (deep, modulus $=50 \mathrm{MPa}$ ) was considered. A cast iron pipe (thickness $=8 \mathrm{~mm}$, modulus $=160 \mathrm{GPa})$ with a diameter of $660 \mathrm{~mm}$ buried below the pavement surface at a depth of $800 \mathrm{~mm}$ was considered. This information was included in a 3-D FE model. Figure 14 shows the maximum tensile stress on the pipe due to a range of axle configurations and tyre loads. Each tyre loading was presented as a circular patch of loading (with a radius $92.1 \mathrm{~mm}$ according to Austroads (2010), and axle configurations were presented according to general axle dimensions used for trucks. The single axle dual tyre (SADT) with a $80 \mathrm{kN}$ axle load represents the "Standard" axle used in pavement design. As can be seen from Fig. 14, different axle and load configurations can give rise to a range of maximum pipe stresses. For this example, the half axle loads per unit stress increase for SAST, SADT, TRDT configurations can be calculated as $70 / 8.5=8.2,40 / 5.8=6.9$ and $150 / 8.9=16.9$, respectively. Using these scaling factors with the assumption of linear material behaviour, the equivalent single tyre loads for the SADT $80 \mathrm{KN}$ axle load can be calculated as $40 / 6.9 * 8.2=47.5$ (the equivalent SAST full axle load is $47.5 * 2=95.0 \mathrm{kN}$ ). Similarly, the equivalent single tyre loads for the TRDT $300 \mathrm{KN}$ axle load can 
be calculated as $150 / 16.9 * 8.2=72.8$ (the equivalent SAST full axle load is $72.8 * 2=145.6 \mathrm{kN}$ ). Similarly, the other axle configurations can be converted to equivalent SAST and the use of a single loading due to one tyre pressure may be appropriate for the development of a practical closed-form stress prediction model. However, the scope of this paper is not to investigate the effect of axle load configurations, but to study the effect of internal and external loadings in buried pipelines.

\subsection{Physical variables for simplified pipe burial conditions}

A series of FE analyses was conducted using the validated 3-D FE model, to investigate a simplified closed-form equation for pipe stress prediction. Figure 15 shows a typical simplified pipe burial condition, especially as applicable to the setting of an old buried water pipe. In old buried pipelines, in most cases, the same native soil has been backfilled and under the present conditions, the presence of a trench to lay the pipe is not discernible. Furthermore, some pipe design methods (e.g., AWWA M11 1999) advocate wide trench design, where the presence of a trench is ignored. Hence, no trench is considered in the simplified pipe setting. Furthermore, to simplify the analysis to a manageable level, the presence of road pavement is also ignored, and it is considered that a single effective modulus representing the pavement and soil can be used to represent the backfill condition. It should be noted that this pipe setting may also be approximately applicable to other scenarios, including where pipes are subjected to loading from construction machinery during pipe laying or road renewal and where pipe is laid in a non-traffic area, and subjected to only soil loads and/or nominal traffic loads.

The level of stress to which pipelines are subjected from traffic loads depends on soil conditions as well as pipe properties (material, sectional and operating properties), in addition to the magnitude of the traffic load $(W)$. From the soil condition perspective, soil modulus $\left(E_{s}\right)$, density $(\gamma)$, lateral earth pressure coefficient $(k)$ and soil Poisson's ratio $\left(v_{s}\right)$ may be dominant. Pipe material modulus and Poisson's ratio $\left(E_{p}, v_{p}\right)$, sectional properties such as thickness $(t)$ and diameter $(D)$, and 
operating pressure $(P)$ can also have significant control on the level of stress to which the pipe is subjected . Eq. 8 summarises the maximum tensile stress of the pipe as a function of identified factors:

$$
\sigma=\phi\left(W, E_{s}, \gamma, k, v_{s}, E_{p}, v_{p}, P, D, t, h\right)
$$

Eq. 8 consists of 11 physical variables. Based on the Buckingham $\pi$ theorem, Eq. 8 can be expressed using an expression involving a set of 9 dimensionless variables as given in Eq. 9:

$$
\left(\frac{\sigma \cdot D^{2}}{W+\gamma \cdot D^{2} \cdot h}\right)=\phi^{\prime}\left(\frac{E_{p}}{E_{s}}, \frac{b}{D}, \frac{D}{t}, \frac{P}{E_{s}}, \frac{E_{s}}{\gamma \cdot h}, k, v_{s}, v_{p}, \frac{W}{\gamma \cdot D^{2} \cdot h}\right)
$$

In the current study, physical variables identified in the problem have been varied within a practical range as summarised in Table 1 to capture the pipeline stress. The range of variables considered was also limited by the overall computational effort needed.

\subsection{Comparison with current analytical models}

The FE results were compared with the results from the model proposed by Spangler (Eq.5) and the Ring models (Eqs. 1 \& 2). Three cases were considered for comparison: Case 1 considered a pipe with diameter $660 \mathrm{~mm}$, wall thickness $8 \mathrm{~mm}$ and modulus $100 \mathrm{GPa}$, placed on stiff soil $\left(E_{s}=50\right.$ MPa). Cases 2 and 3 considered the same pipe placed on soft soil $\left(E_{s}=10 \mathrm{MPa}\right)$ and very soft soil $\left(E_{s}\right.$ $=2 \mathrm{MPa}$ ), respectively. The case of very soft soil may also be used to represent situations where the contribution of soil to pipe deformation is not certain. The tested traffic load configuration in all the cases was SAST with a tyre load of $20 \mathrm{kN}$.

Table 4 compares the pipe maximum tensile stress derived from Ring model and the Spangler model against the results from FE analyses. Although the Spangler model predicts similar stresses compared to FE analyses for pipe placed on stiffer soil, pipe stresses are over-predicted in soft soils by $56 \%$ and $69 \%$ for the 'soil' and 'soil+traffic' load cases respectively. On the other hand, the Ring model heavily over-predicts the stresses from both the Spangler and FE models. In addition, the results from the Ring model do not differentiate between stiff and soft soils. 
The main reason for the heavy over-prediction of the Ring model (Eq.1) is due to the lack of lateral support provided in the model derivation. However, the modified Ring model (Eq.2) predicts lower pipe stresses as a result of the incorporation of lateral earth support, but the stresses are independent of the soil stiffness. Although the Spangler model incorporates lateral soil resistance, the model is unable to consider re-distribution of stresses in a highly stressed pipe, for instance, when the pipe is buried in soft soils. In other words, the three-dimensional effect of the pipe helps re-distribute the pipe stresses in the longitudinal direction, as shown in Fig. 16. Figs. 17(a) and 17(b) show a comparison of vertical stress distribution in soil directly above the pipe crown in longitudinal and lateral horizontal directions. It is clear that the 3-D stress analysis shows peaking of stress under the traffic load and decay of stress in both lateral and longitudinal directions. In contrast, the stress predicted by the Spangler model remains constant over the pipe diameter, indicating a limitation in its assumptions.

\section{New Pipe Stress Prediction Equation}

The validated numerical model of the pipe-soil system was used to compute the maximum stress in different pipe burial conditions, as given in Table 1 . These conditions included a range of pipe diameters, pipe wall thicknesses, soil conditions, traffic loads and internal pressure conditions. The ranges of parameters were chosen so that computer run times were kept manageable. In a computer with 12 processors (each running at $2.67 \mathrm{GHz}$ ) and $128 \mathrm{~GB}$ of physical memory, each parametric run took 3-8 hours and altogether 830 runs were undertaken.

The maximum pipe tensile stress values computed from the numerical models were used to develop the pipe stress prediction equation as a function of the non-dimensional parameter groups given in Eq. (9) using nonlinear regression, as detailed below.

\subsection{Nonlinear regression}

The basic idea of nonlinear regression is to relate a response $Y$ to a vector of predictor variables $\mathbf{x}=\left(x_{1}, x_{2}, \ldots \ldots x_{k}\right)^{T}$. Nonlinear regression is characterized by the fact that the prediction equation 
depends nonlinearly on one or more unknown parameters. A nonlinear regression model has the general form of;

$$
Y_{i}=f\left(\mathbf{x}_{\mathbf{i}}, \boldsymbol{\theta}\right)+\varepsilon_{i} \quad i=1,2 \ldots, n
$$

where, $Y_{i}$ are responses, $f$ is a known function of the covariate vector $\mathbf{x}_{i}=\left(x_{i 1}, x_{i 2}, \ldots \ldots x_{i k}\right)^{T}$ and the parameter vector $\boldsymbol{\theta}=\left(\theta_{1}, \theta_{2}, \ldots, \theta_{p}\right)^{T}$ and $\varepsilon_{i}$ are random errors. $\varepsilon_{i}{ }^{\prime} s$ are usually assumed to be uncorrelated with mean zero and constant variance. It is customary and convenient to minimize the sum of the weighted squares of the errors between the measured responses $\left(Y_{i}\right)$ and the predicted responses $\left[Y_{i}\left(x_{i}, \boldsymbol{\theta}\right)\right]$.This scalar-valued goodness-of-fit measure is called the chi-squared error criterion $\chi^{2}(\boldsymbol{\theta})$. If the function $Y$ is nonlinear in the model parameters $\boldsymbol{\theta}$, then the minimisation of $\chi^{2}$ with respect to the parameters must be carried out iteratively. In this study, the LevenbergMarquardt method was used to minimise the $\chi^{2}$ and find appropriate model parameters (Marquardt, 1963; Levenberg, 1944).

\subsection{Equation development}

The stress prediction equation was developed for the pipes buried in both soft (represented by $2 \mathrm{MPa}$ modulus) and stiff soils (represented by $50 \mathrm{MPa}$ modulus) subjected to traffic load and internal pressure. A number of trials with varying success were undertaken to devise a suitable equation relating the non-dimensional quantities. Based on both the Spangler and Schilck (1940) equations, the following closed-form equation is proposed to compute the maximum pipe tensile stress:

$$
\frac{\sigma \cdot D^{2}}{W+\gamma \cdot D^{2} \cdot h}=\alpha_{1}\left(\frac{E_{p}}{E_{s}}\right)^{\beta_{1}}\left(\frac{E_{s}}{\gamma \cdot h}\right)^{\beta_{2}}\left(\alpha_{2} \frac{\left(\frac{P}{E_{s}}\right)^{\beta_{3}}}{\left(\frac{t}{D}\right)^{\beta_{4}}\left(\frac{W}{\gamma \cdot D^{2} \cdot h}+1\right)^{\beta_{5}}}+\alpha_{3} \frac{\left(\frac{t}{D}\right)^{\beta_{6}}\left(\frac{W}{\gamma \cdot D^{2} \cdot h}+1\right)^{\beta_{7}}}{\alpha_{4}\left(\frac{E_{p}}{E_{s}}\right)+\alpha_{5}\left(\frac{P}{E_{s}}\right)+\alpha_{6}\left(\frac{h}{D}\right)+\alpha_{7} k}\right)
$$

It is worth noting that in Eq. 11 the maximum pipe tensile stress is explicitly given by a closed-form expression of non-dimensional quantities on the right-hand side. In other words, if we know $W$ and $P$, 
we can compute the maximum stress directly, using a calculator or a spreadsheet. Table 5 gives the regressed model coefficients in Eq. 11. The comparison of the stresses and the errors in prediction using the proposed equation and the numerical model is shown in Fig. 18. As the figure shows, the proposed form of the equation is capable of predicting the stress with high accuracy (i.e., $\mathrm{R}^{2}=0.99$ ), with maximum stress variation in the range of 5 to $10 \mathrm{MPa}$.

Independent validation of the proposed equation was carried out using the random values of parameters at different levels. Figure 19 shows the proposed equation predictions against the numerical model predictions.

\subsection{Model verification}

The proposed model was verified by comparing the predictions against the data obtained from the field experiments. The results were compared for several incremental pressure loadings (i.e. $\mathrm{P}=200 \mathrm{kPa}, 350 \mathrm{kPa}$ and $690 \mathrm{kPa}$ ), as well as for a combination of water pressure and traffic loading (i.e. $\mathrm{P}=523 \mathrm{kPa} \& \mathrm{~W}=30 \mathrm{kN}$ ). Figure 20 shows the maximum stresses derived from the proposed solution compared with the field data. The stresses on the field pipe were obtained using the circumferential and longitudinal strains derived from the strain gauges. The results show that the proposed model is sufficiently capable of capturing the maximum pipe stress obtained on the basis of field strains at various pressure and traffic loadings. Therefore, it is argued that the model can be used reliably to predict the maximum pipe stress of uniform pipes subjected to operational loads of internal water pressures (i.e. $100 \mathrm{kPa}$ to $600 \mathrm{kPa}$ ) and external traffic loads (i.e. 0 to $40 \mathrm{kN}$ ).

\subsection{Parameter Sensitivity and Model Application}

A sensitivity analysis was conducted to investigate the relative influence of the governing physical variables on pipe stress. In this study, Spearman's rank correlation coefficient (Spearman, 1904), which is a nonparametric measure of statistical dependence between two variables, was computed for each controlling variable with the maximum pipe stress computed. The correlation coefficient computed was normalised to find the relative contribution of each parameter on the pipe stress. Figure 21 shows the relative contribution to stress of each parameter as a percentage. From Fig. 21, it can be 
seen that the internal water pressure and pipe wall thickness have a greater influence (i.e., more than $20 \%$ ) than traffic load, soil modulus, soil cover and lateral earth pressure coefficient (i.e., below $10 \%)$.

Fig. 22 shows a set of interaction curves for maximum pipe tensile stress for a range of pipe burial conditions. The interaction curves shown by the solid lines are based on Eq. 11 and the curves shown in dashed lines are from the 3-D numerical analyses. The closeness of the two predictions also verifies the applicability of the proposed stress prediction equation (i.e., Eq. 11). The operating ranges shown in these figures are chosen to reflect typical traffic loads from 0 to $150 \mathrm{kN}$, which could be considered as a single wheel load in a single axle single tyre axle or the equivalent load from a truck load with multiple axles and tyres. Even in a global sense, this level of traffic loading is appropriate (Rajani and Abdel-Akher 2012). The range of water pressure is considered up to $1500 \mathrm{kPa}$, which can include static and possible transient pressures during certain network operations such as valve closure or pump shutdown.

One important thing to observe is the slope of the interaction curve with the pressure axis close to the zero traffic load. As shown in Fig. 23, this gradient is less than 90 degrees or vertical at the point where the interaction line meets the pressure axis, which is the case in the Schlick framework. When the data used to generate the Schlick diagram were further examined, it became evident that there were very few original data in the operating region given here. Most of the data were in the high traffic load region, since it was much easier to fail the test pipes by increasing the vertical load in contrast to increasing the internal pressure. Therefore, their vertical exit of the interaction lines at the pressure axis was not properly validated. The important implication of this finding is as follows. The dominant variable that leads to a large majority of pipe stress is the internal water pressure. However, according the Schlick curve, the importance of increasing traffic load (from the internal pressure axis) is not very significant, since the interaction curve is almost vertical in this region. In other words, to obtain the same pipe stress, the internal water pressure would be almost the same even if the traffic load increased to a significant level. However, with a lower gradient as indicated by the model proposed (Eq. 11), the same pipe stress can be reached at lower pressures as the traffic load increases. 
In other words, the significance of the traffic load for pipe stress generation is exemplified in the operating region, as can also be seen from the sensitivity analysis given in Fig. 21.

The possible application of the model developed is highlighted here with the aid of two examples.

Example 1: Assessment of existing pipe performance using the proposed equation

Consider a cast iron pipe $660 \mathrm{~mm}$ in diameter and $15 \mathrm{~mm}$ in thickness buried at a depth of $0.8 \mathrm{~m}$. The pipe is subjected to an estimated maximum of equivalent single $50 \mathrm{kN}$ of traffic load and $900 \mathrm{kPa}$ of internal pressure, which includes a component of transient pressure. The following input parameters are estimated: the elastic modulus of the pipe is $100 \mathrm{GPa}$ and the tensile capacity is $100 \mathrm{MPa}$, the soil density is $20 \mathrm{kN} / \mathrm{m}^{3}$, the soil modulus is $25 \mathrm{MPa}$ and the lateral earth pressure coefficient is 0.4 .

Figure 24 shows the load-pressure interaction diagram for the pipe, developed from Eq. 11. Point A denotes the pipe at the operating condition, under which the pipe experiences a maximum tensile stress of 25.3 MPa. Of course, the pipe has excessive capacity since the failure stress is $100 \mathrm{MPa}$. Figure 24 also shows the $100 \mathrm{MPa}$ stress line and in order for the pipe to fail by increasing pressure only, the pipe internal water pressure needs to increase by as much as $4075 \mathrm{kPa}$ (marked as B). Therefore, under the current operation conditions, this pipe is not likely to fail in the short term and the factor of safety against failure may be given as 4075/900, which is almost 4.53. However, it should be noted that stress concentration due to corrosion defect may raise the uniform stress, but this aspect is not considered here.

\section{Example 2: Assessment of remaining life of the pipe}

Consider the same pipe shown in Example 2 with the associated input conditions. Assuming the current average corrosion rate applicable to the buried environment is $0.2 \mathrm{~mm} / \mathrm{year}$, what is the remaining life of the pipe?

The maximum pipe stress is calculated for pipe thicknesses of $15 \mathrm{~mm}, 10 \mathrm{~mm}, 5 \mathrm{~mm}$ and $3.2 \mathrm{~mm}$, as the pipe thickness degrades with corrosion. Therefore, as the pipe thickness degrades, the maximum pipe stress progressively increases to $25.51 \mathrm{MPa}, 36.4 \mathrm{MPa}, 67.0 \mathrm{MPa}$ and $100 \mathrm{MPa}$ respectively. Therefore, when the pipe wall thickness reaches $3.2 \mathrm{~mm}$, the maximum stress in the pipe will reach 
the ultimate strength of $100 \mathrm{MPa}$ and the pipe will fail. Hence, the remaining life from the current condition can be estimated as the time to reach a pipe thickness of $3.2 \mathrm{~mm}$ or 59 years (i.e., (153.2)/0.2). Again, the uniform corrosion concept, which assumes the pipe wall corroded evenly around the perimeter, is used in the calculation.

\section{Conclusions}

The equations currently available for the estimation of maximum stress in buried pipes were examined, paying special attention to existing water pipe lines. Since a uniform pipe wall thickness is considered, it is assumed that the pipe has undergone general corrosion and the condition can be approximated by a reduced wall thickness. The results of the current stress equations were compared with solutions obtained from 3-D finite element analyses. It was found that the current methods generally over-predict the pipe stresses to varying degrees, depending on the simplifying assumptions used to make the problem solvable as a statically determinate problem. Such over-estimation of stress may mean condemning a pipe prematurely, when it has a substantial remaining life. To address the limitations identified in these equations but develop a simplified solution for practical use by water authorities, a new closed-form solution has been developed to compute the maximum pipe stress using a combination of non-dimensional analysis, 3-D FE analysis and non-linear regression. The equation is explicit, meaning that it can be directly used, using either a calculator or a spreadsheet, to compute stresses once the main external and internal factors are estimated. The proposed equation may be useful in probabilistic analyses where a large number of calculations need to be carried out to account for the uncertainty of the input variables. The results of the equation can also be presented in interaction diagrams of traffic load and internal pressure, similar to the Schlick curve used in pipe design. The use of the new equation and the interaction diagrams in pipe stress assessment have been demonstrated with the help of two examples. It is found that close to the pressure axis (low traffic load region), the Schlick curve may not be highly accurate, and this observation may need to be verified with more experimental results since there were few experimental results in this region in the original Schlick curve development. It should also be noted that the new equation has been developed for a range of operating conditions. Therefore, its validity outside this range needs to be checked 
further prior to its use in pipe settings outside these operating conditions. The equation is suitable to be used in the evaluation of the remaining life of old pipes where the effects of initial trenching can be ignored. As confirmed by many old pipe exhumations, the trenches of old pipes (prior to the 1960s) were backfilled with the same soil and the effect of initial trenching has disappeared due to the long burial duration.

\section{Acknowledgements}

This publication is an outcome from the Advanced Condition Assessment and Pipe Failure Prediction Project funded by the Sydney Water Corporation, the Water Research Foundation of the USA, Melbourne Water, the Water Corporation (WA), UK Water Industry Research Ltd, South Australia Water Corporation, South East Water, Hunter Water Corporation, City West Water, Monash University, the University of Technology, Sydney and the University of Newcastle. The research partners are Monash University (lead), the University of Technology Sydney and the University of Newcastle.

\section{References}

ABAQUS, Inc. 2011. ABAQUS V.6.7 User's Manual, Providence, Rhode Island.

American Water Works Association. 1999. Steel Pipe - A Guide for Design and Installation. AWWA Manual M11, 3rd Edition, US.

Austroads. 2010. Pavement Design-A Guide to the Structural Design of Road Pavements, Austroad Inc.2010, Australia.

Levenberg, K. 1944. A Method for the Solution of Certain Non-Linear Problems in Least Squares. The Quarterly of Applied Mathematics, 2: 164-168.

Marquardt, D.W. 1963. An algorithm for least-squares estimation of nonlinear parameters. Journal of the Society for Industrial and Applied Mathematics, 11(2):431-441.

Masada, T. 2000. Modified Iowa Formula for Vertical Deflection of Buried Flexible Pipe, ASCE Journal of Transportation Engineering, September/October, 2000.

Marston, A., and Anderson, A.O. 1913. The Theory of Loads on Pipes in Ditches and Tests of Cement and Clay Drain Tile and Sewer Pipe. Bulletin 31, Iowa Engineering Experiment Station, Ames, Iowa. 
Moser, A. P., and Folkman, S. 2008. Buried Pipe Design, Mc Graw Hill, New York.

Potyondy, J.G. 1961. Skin friction between various soils and construction materials. Geotechniques, 11(4): 339-353.

Rajani, B., and Abdel-Akher, A. 2012. Re-assessment of resistance of cast iron pipes subjected to vertical loads and internal pressure. Engineering Structures, 45:192-212.

Schlick, W.J. 1940. Supporting strength of cast iron pipe for gas and water services. Bulletin No. 146, Iowa Engineering Experimental Station, Ames, IA.

Spangler, M.G. 1941. The Structural Design of Flexible Pipe Culverts. Bulletin 153, Iowa Engineering Experiment Station, Ames, Iowa.

Spearman, C. 1904. The proof and measurement of association between two things. Amer. J. Psychol. 15: $72-101$.

Young, O.C., and Trott, J.J. 1984. Buried Rigid Pipes. Elsevier, London.

Warman, D.J., Hart, J.D. and Francini, R.B. 2009. Development of a pipeline surface loading screening process and assessment of surface load dispersing methods, Report 05-44R1, Canadian Energy Pipeline Association.

Watkins, R. K. and Anderson, L.R. 1999. Structural Mechanics of Buried Pipes, CRC Press, Taylor \& Francis Group. New York.

Watkins, R.K. and Anderson, L.R. 2000. Structural Mechanics of Buried pipes. CRC Press, New York.

Watkins, R.K., and Smith, A.B. 1967. Ring deflection of buried pipe, Amer. Water Works Association Journal , 59:367-378.

\section{List of Figures}

Figure 1 Assumed soil stress distributions around a rigid pipe for loose and dense sidefill (adapted from Watkins and Anderson 2000)

Figure 2 Assumed soil stress distribution around pipe (adapted from Masada 2000), where $W_{c}$ equals $W_{\text {vertical }}$

Figure 3 Model dimensions and mesh discretization of the finite element model

Figure 4 Instrumentation on pipe section in the field test.

Figure 5 Triaxial test data based on samples from test bed soil

Figure 6 Comparison of pipe deformation and stresses between 3-D FE model and field data using a small truck load (SAST axle load 4.85t)

Figure 7 Comparison of the soil stress at the pipe level between FE model and in the field using a small truck load (SAST axle load 4.85t)

Figure 8 Comparison of the circumferential strain development between FE pipe model and field instrumented pipe under different water pressure loadings 
Figure 9 Comparison of (a) circumferential strain and (b) circumferential stress development between FE pipe model and field instrumented pipe at water pressure $523 \mathrm{kPa}$ and $5.78 \mathrm{t}$ axle load (SAST)

Figure 10 Comparison of the pipe maximum circumferential stress and soil vertical stress variation between elastic and plastic soils under water pressure loading

Figure 11 Comparison of the pipe maximum circumferential stress variation between elastic and plastic soils under different traffic loadings

Figure 12 Stress paths of elements (a) at the ground surface (b) at the pipe level in $\pi$ plane

Figure 13 Effect of interface friction between pipe and soil under various traffic load magnitudes

Figure 14 Variation of maximum tensile stress due to different axle and load configurations.

Figure 15 Typical simplified pipe burial conditions

Figure 16 Pipe circumferential (hoop) stress plotted along the pipe length

Figure 17 Vertical soil stresses plotted on top of the pipe (a) Lateral direction and (b) Longitudinal direction

Figure 18 (a) Comparison of predictions from the numerical model and the proposed equation, (b) errors in the prediction together with fitted normal distribution

Figure 19. Comparison of proposed equation and numerical model prediction

Figure 20. Comparison of proposed model outcomes with the field test data

Figure 21 Results of the sensitivity analysis

Figure 22 Comparison of predicted maximum stress using the proposed model and numerical model simulation for pipe subjected to traffic load and internal pressure $(\mathrm{k}=0.4, \mathrm{Ep}=100 \mathrm{GPa}, \gamma=19.13$ $\mathrm{kN} / \mathrm{m}^{3}$ )

Figure 23 Schematic Schlick diagram

Figure 24 Load- pressure interaction diagram for example 1 


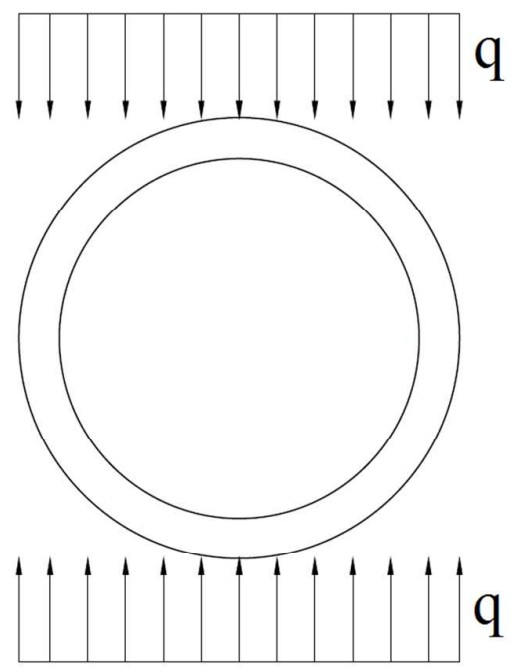

(a) Loose sidefill

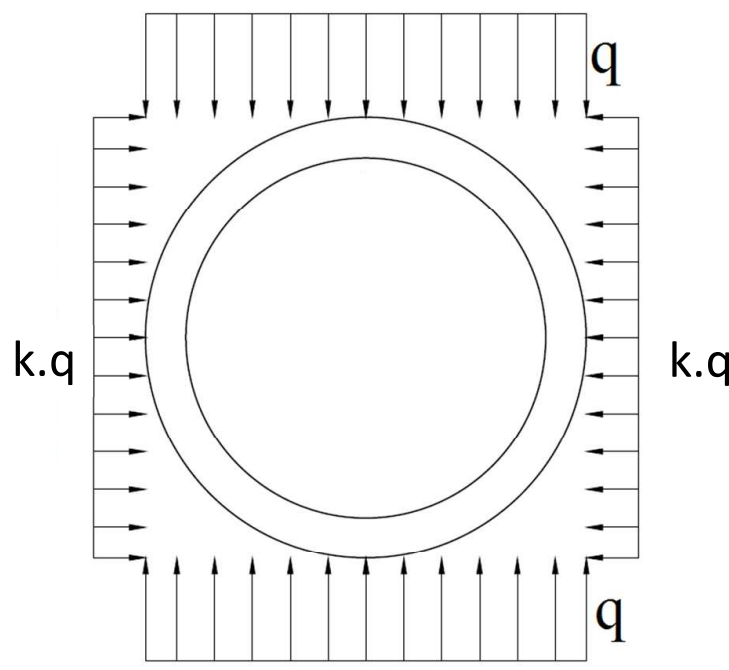

(b) Dense sidefill

Figure 1 Assumed soil stress distributions around a rigid pipe for loose and dense sidefill (revised from Watkins and Anderson 2000) 


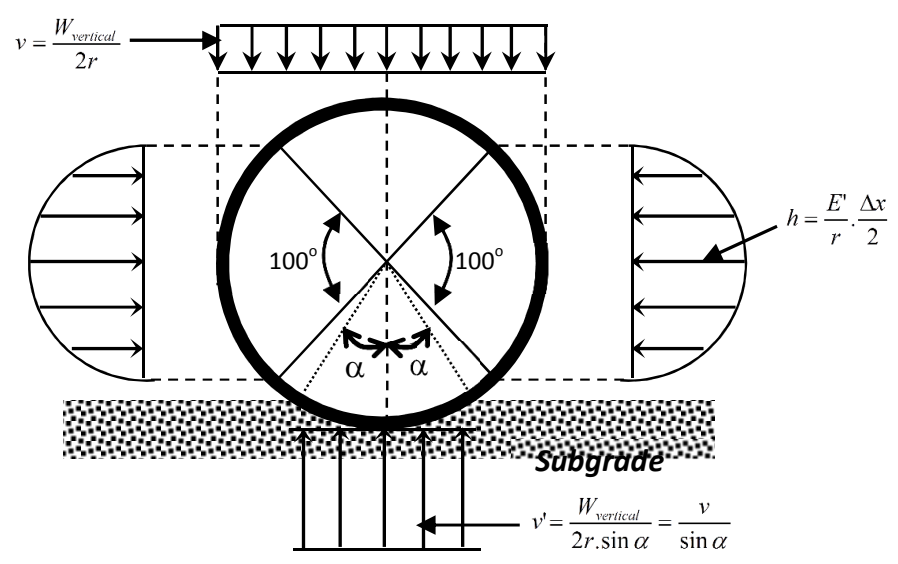

Figure 2 Assumed soil stress distribution around pipe (revised from Masada 2000)

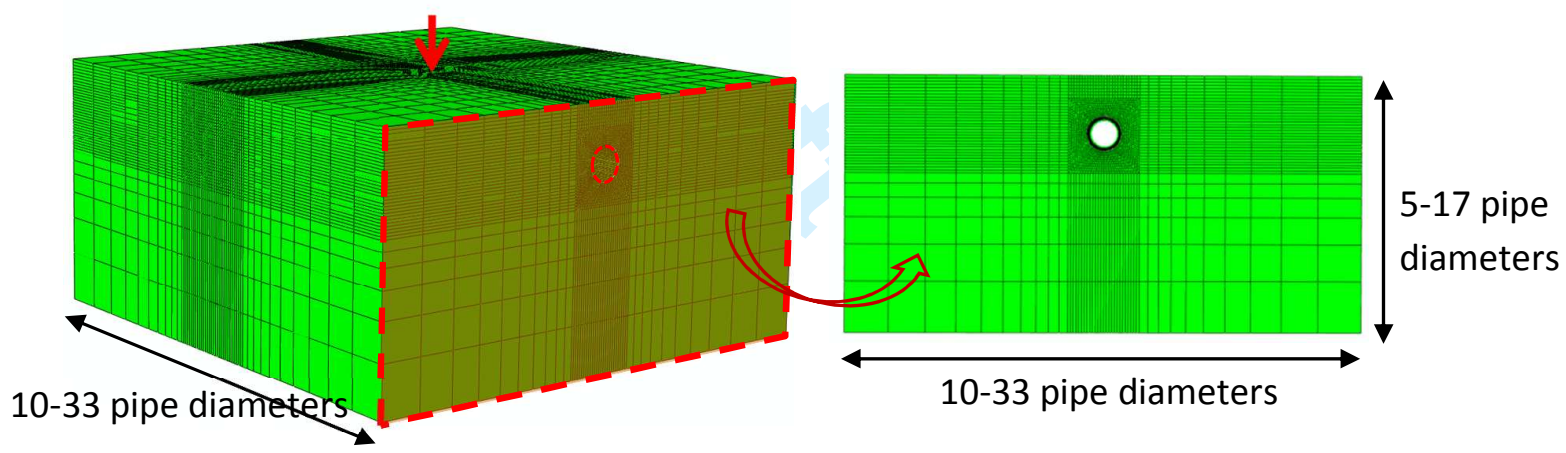

Figure 3 Model dimensions and mesh discretization of the finite element model 


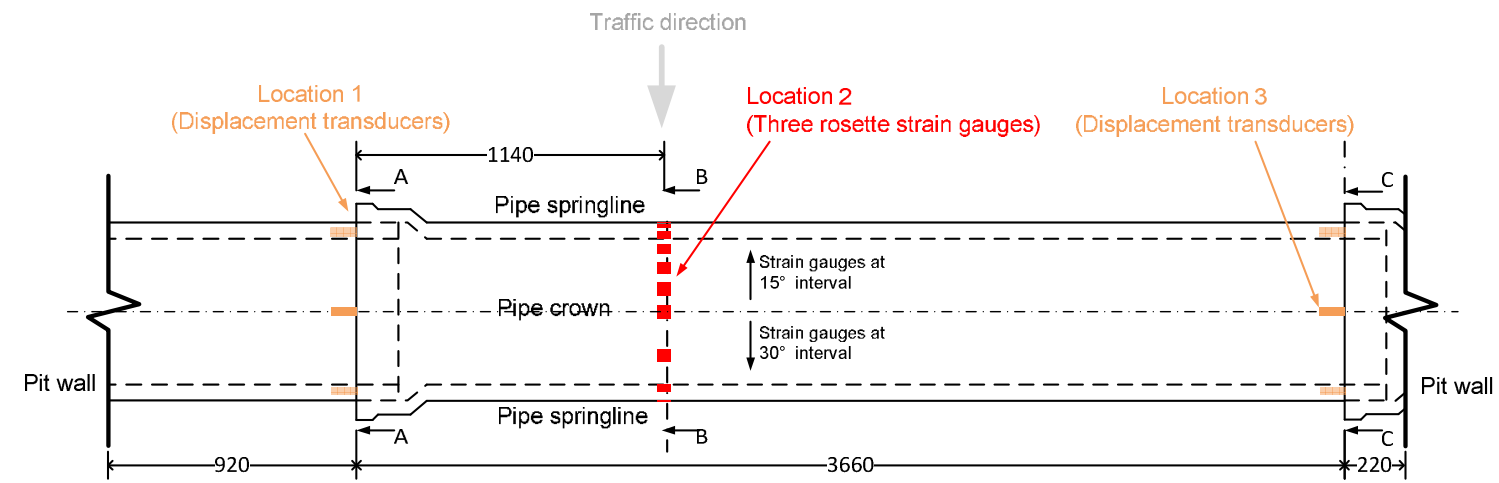

Plan view

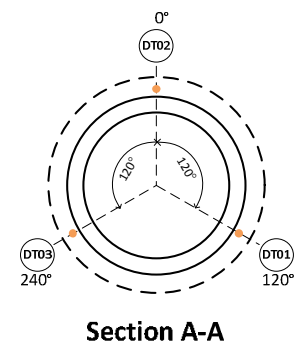

Section A-A

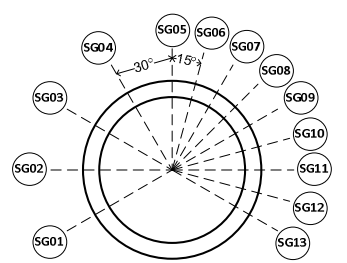

Section B-B
13 active three rosette strain gauges (thermally compensated)

6 joint displacement transducers

Figure 4 Instrumentation on pipe section in the field test

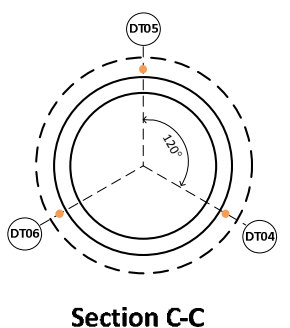

Section C-C

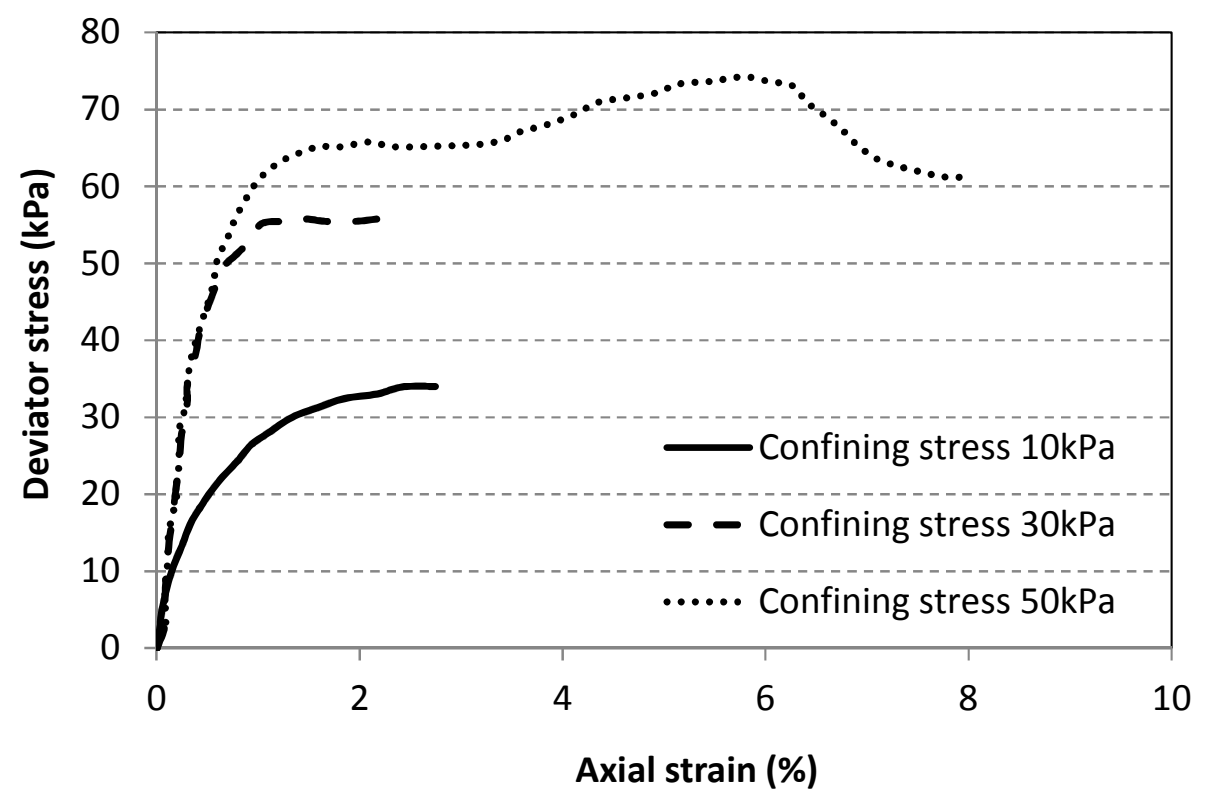

Figure 5 Triaxial test data based on samples from test bed soil 


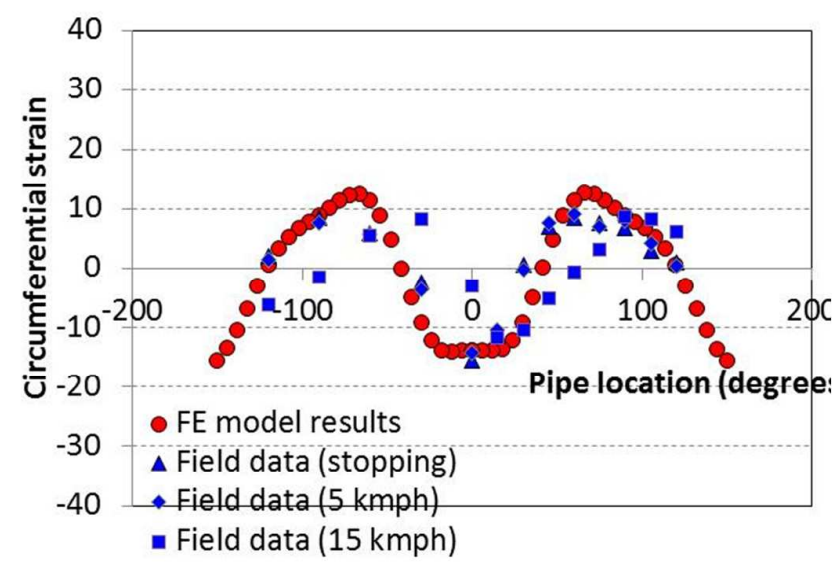

(a) Pipe deformation

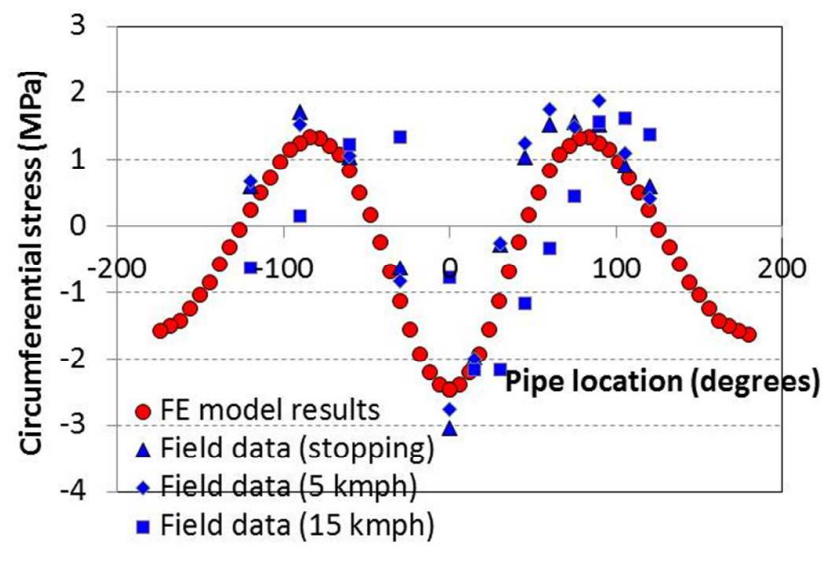

(b) Pipe stresses

Figure 6 Comparison of pipe deformation and stresses between 3D FE model and field data using a small truck load (SAST axle load 4.85t)

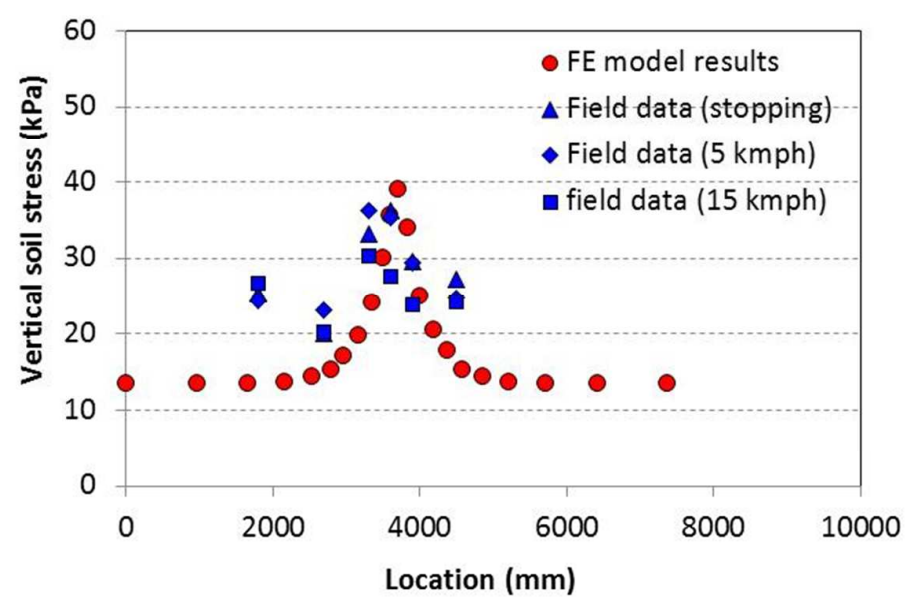

Figure 7 Comparison of the soil stress at the pipe level between FE model and in the field using a small truck load (SAST axle load 4.85t) 

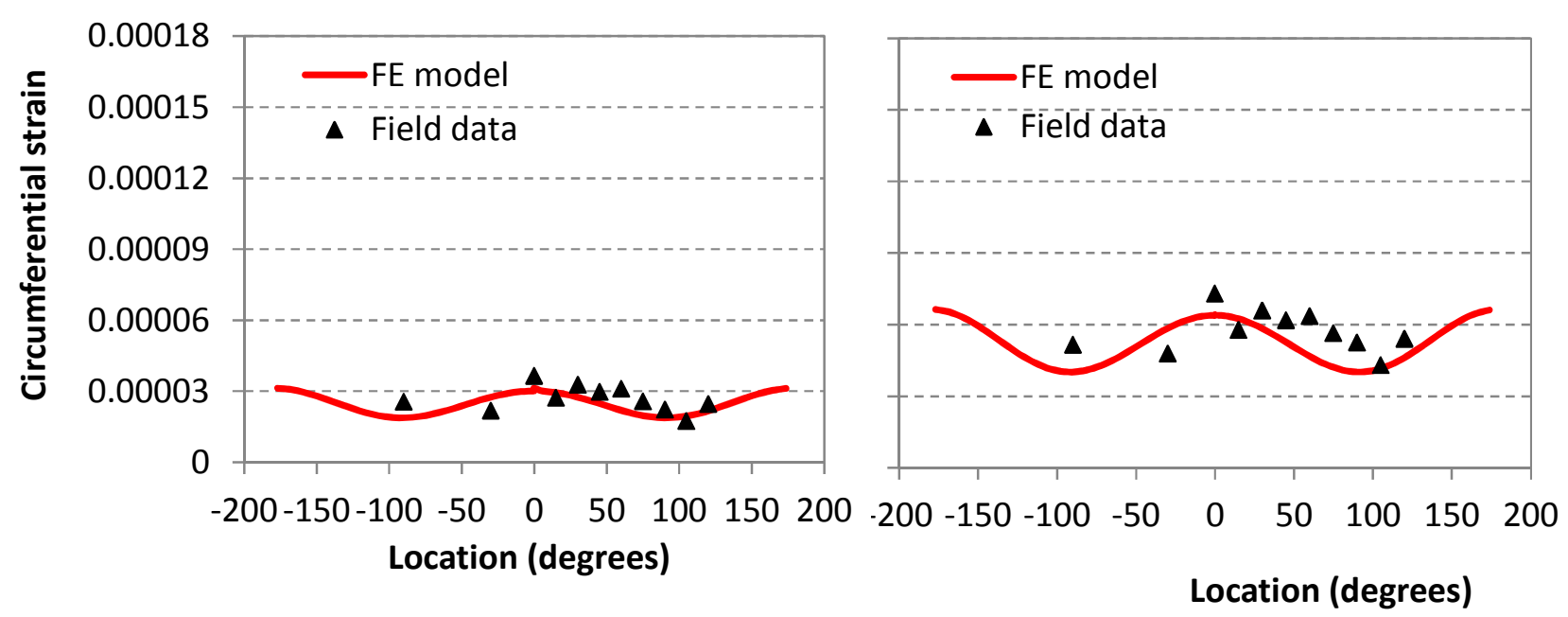

(a) At water pressure $200 \mathrm{kPa}$

(b) At water pressure $350 \mathrm{kPa}$
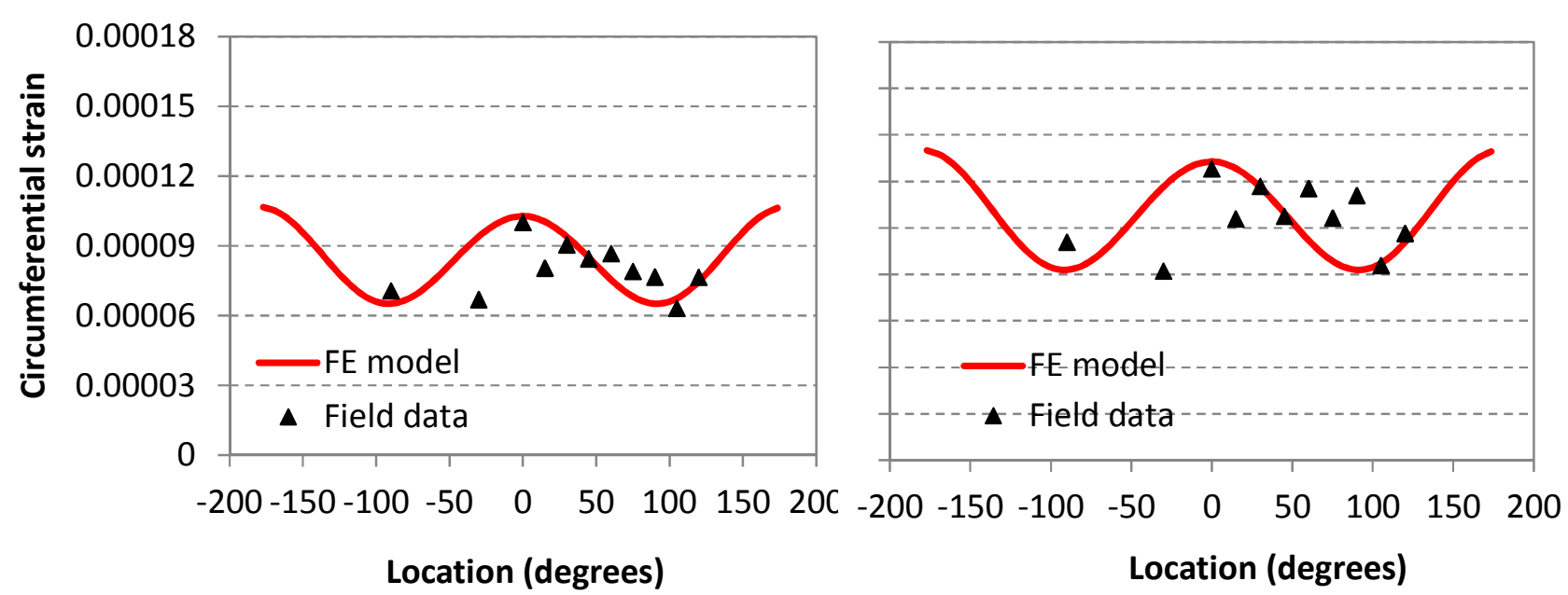

(a) At water pressure $550 \mathrm{kPa}$

(d) At water pressure $690 \mathrm{kPa}$

Figure 8 Comparison of the circumferential strain development between FE pipe model and field instrumented pipe under different water pressures loading 

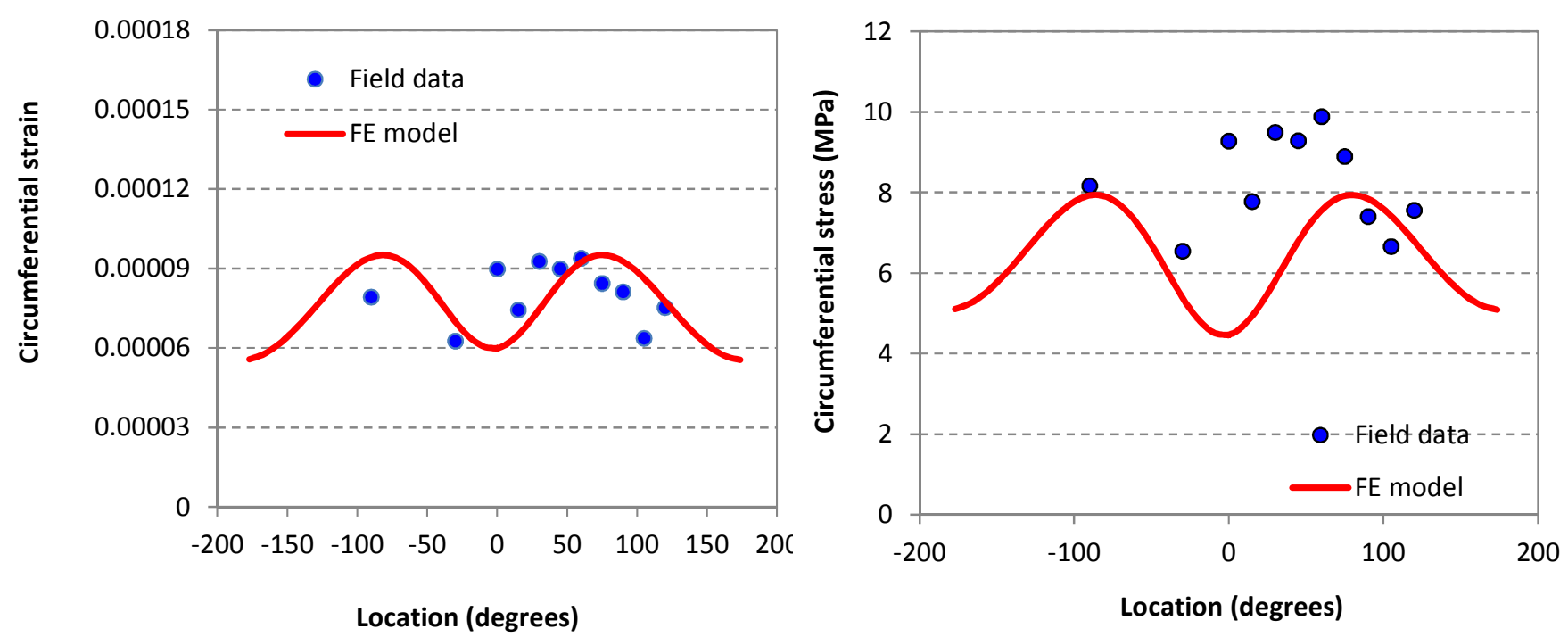

Figure 9 Comparison of the (a) circumferential strain and (b) circumferential stress development between FE pipe model and field instrumented pipe at water pressure $523 \mathrm{kPa}$ and $5.78 \mathrm{t}$ axle load (SAST)

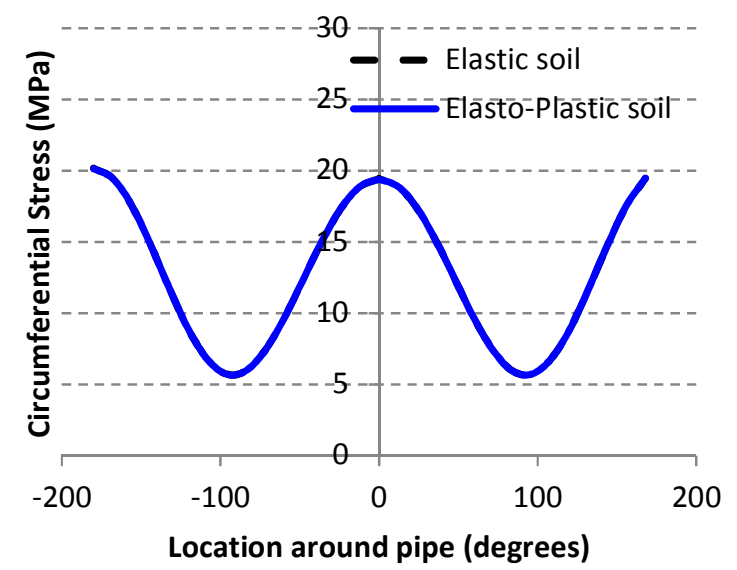

(a) Pipe circumferential stress

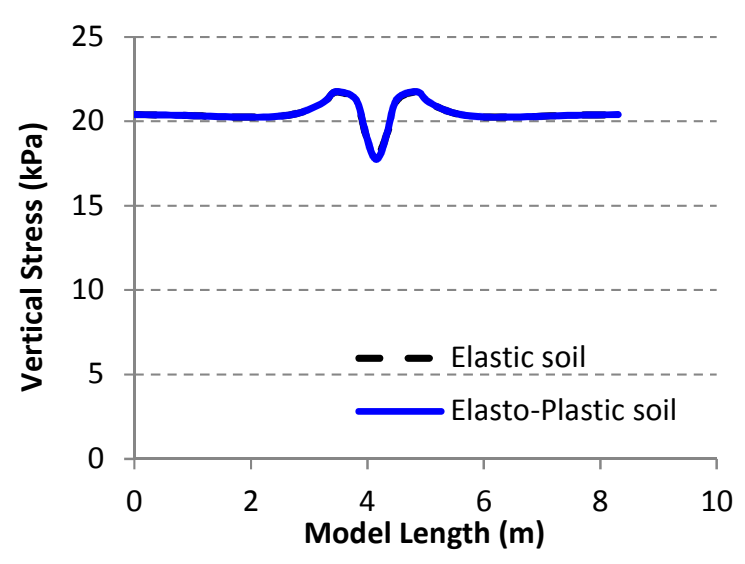

(b) Soil vertical stress

Figure 10 Comparison of the pipe maximum circumferential stress and soil vertical stress variation between elastic and plastic soils under water pressure loading 


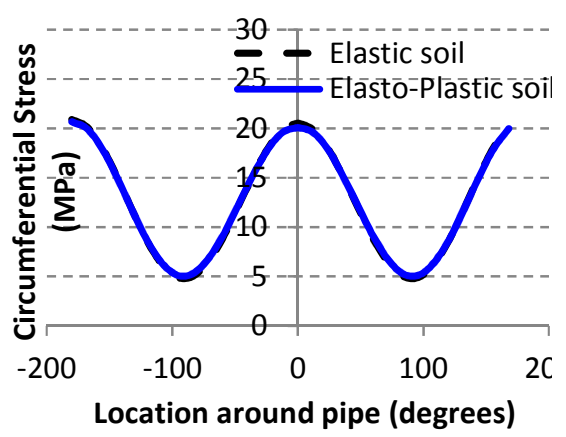

(a) Traffic Loading $=10 \mathrm{kN}$

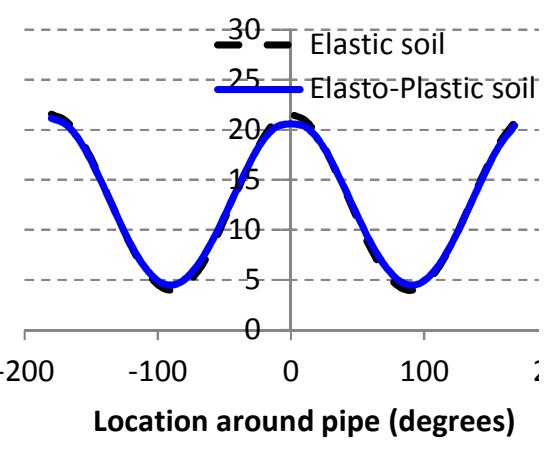

(b) Traffic Loading $=20 \mathrm{kN}$

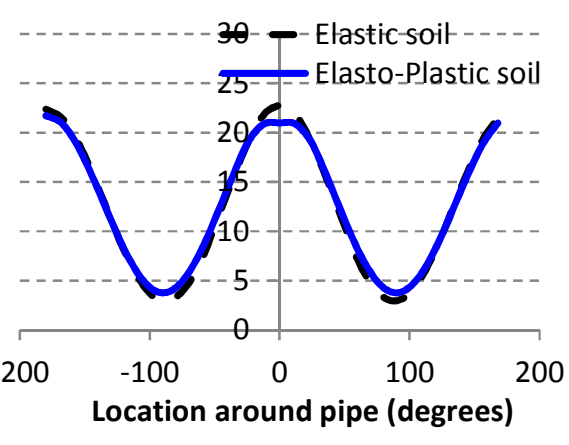

(c) Traffic Loading $=30 \mathrm{kN}$

Figure 11 Comparison of the pipe maximum circumferential stress variation between elastic and plastic soils under different traffic loading

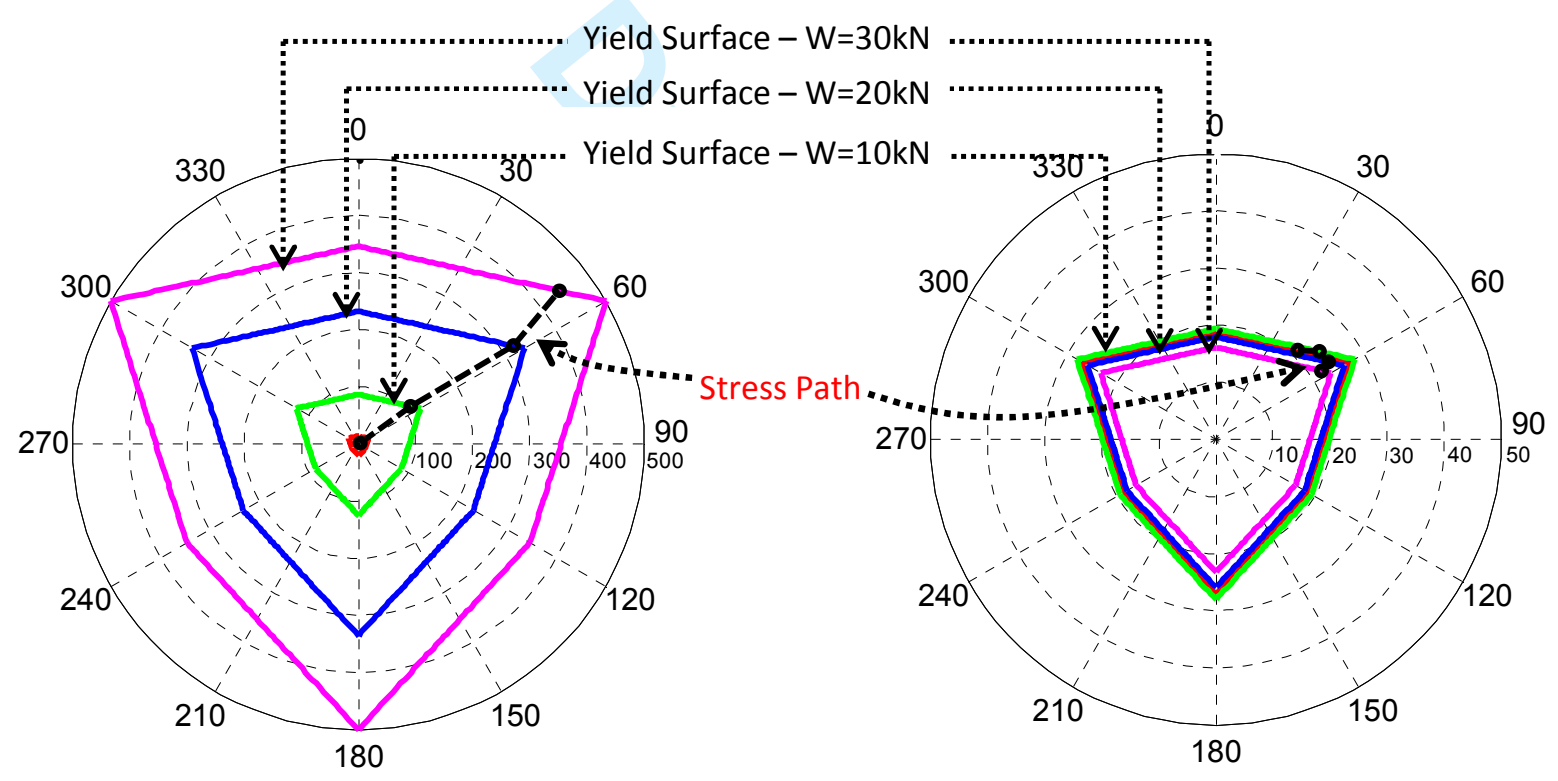

(a) Stress path of element at the ground surface

(b) Stress path of element at the pipe level

Figure 12 Stress paths of elements (a) at the ground surface (b) at the pipe level in $\pi$ plane 


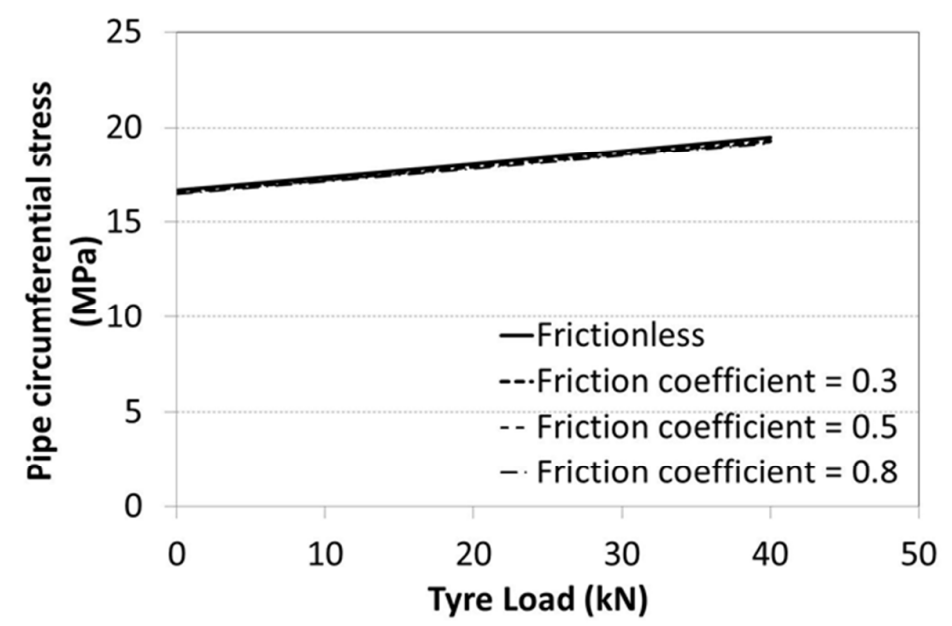

Figure 13 Effect of interface friction between pipe and soil under various traffic load magnitudes

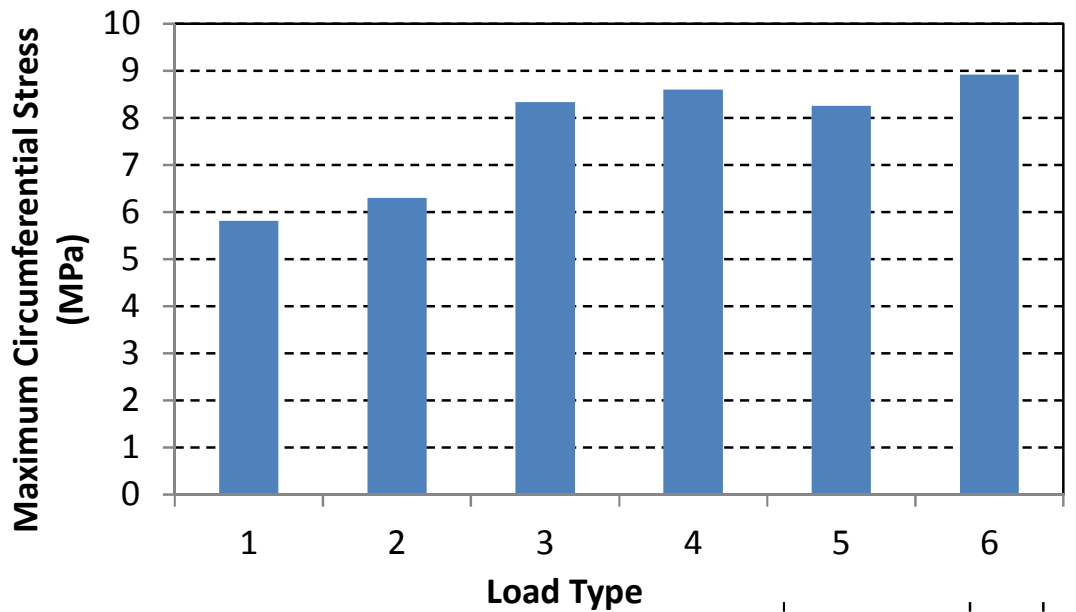

1=SADT - Lateral Alignment $(80 \mathrm{kN}$ Axle Load)

2=SADT - Longitudinal Alignment (80kN Axle Load)

$3=$ SAST - Lateral Alignment (140kN Axle Load)

4=SAST - Longitudinal Alignment (140kN Axle Load)

$5=$ TRDT - Longitudinal Alignment (300kN Axle Load)

6=TRDT - Lateral Alignment (300kN Axle Load)

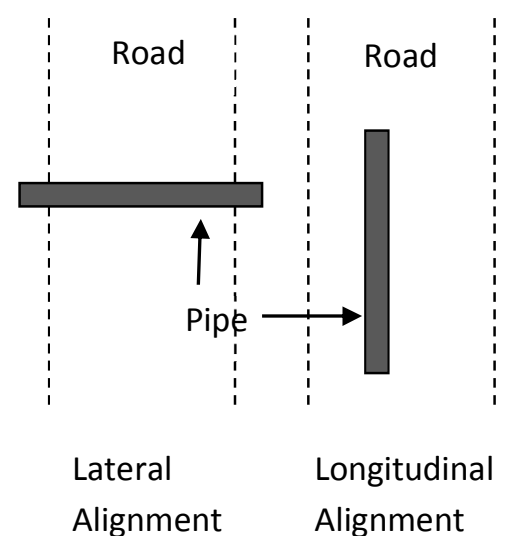

Figure 14 Variation of maximum tensile stress due to different axle and load configurations. 


\begin{tabular}{|c|c|}
\hline Description & Symbol \\
\hline Pipe diameter & $D$ \\
\hline Pipe thickness & $t$ \\
\hline Pipe stiffness & $E_{p}$ \\
\hline Pipe Poisson's ratio & $v_{p}$ \\
\hline Soil stiffness & $E_{s}$ \\
\hline Soil Poisson's ratio & $v_{s}$ \\
\hline Soil density & $\gamma$ \\
\hline Soil lateral earth pressure coefficient & $k$ \\
\hline Cover height & $h$ \\
\hline Internal water pressure & $P$ \\
\hline Traffic load & $W$ \\
\hline
\end{tabular}

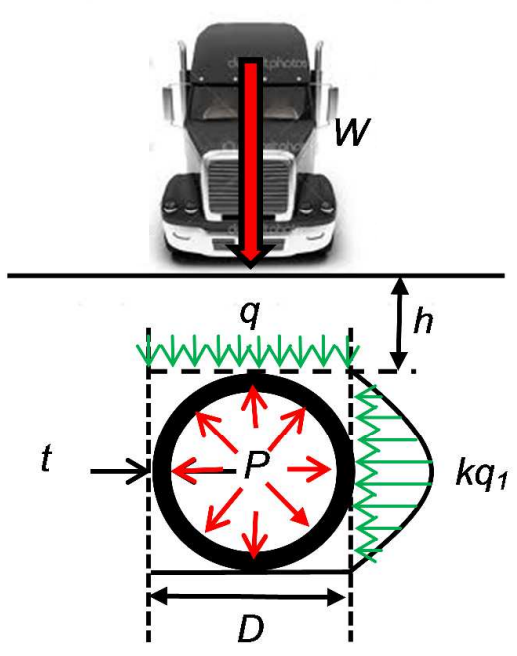

Figure 15 Typical simplified pipe burial condition

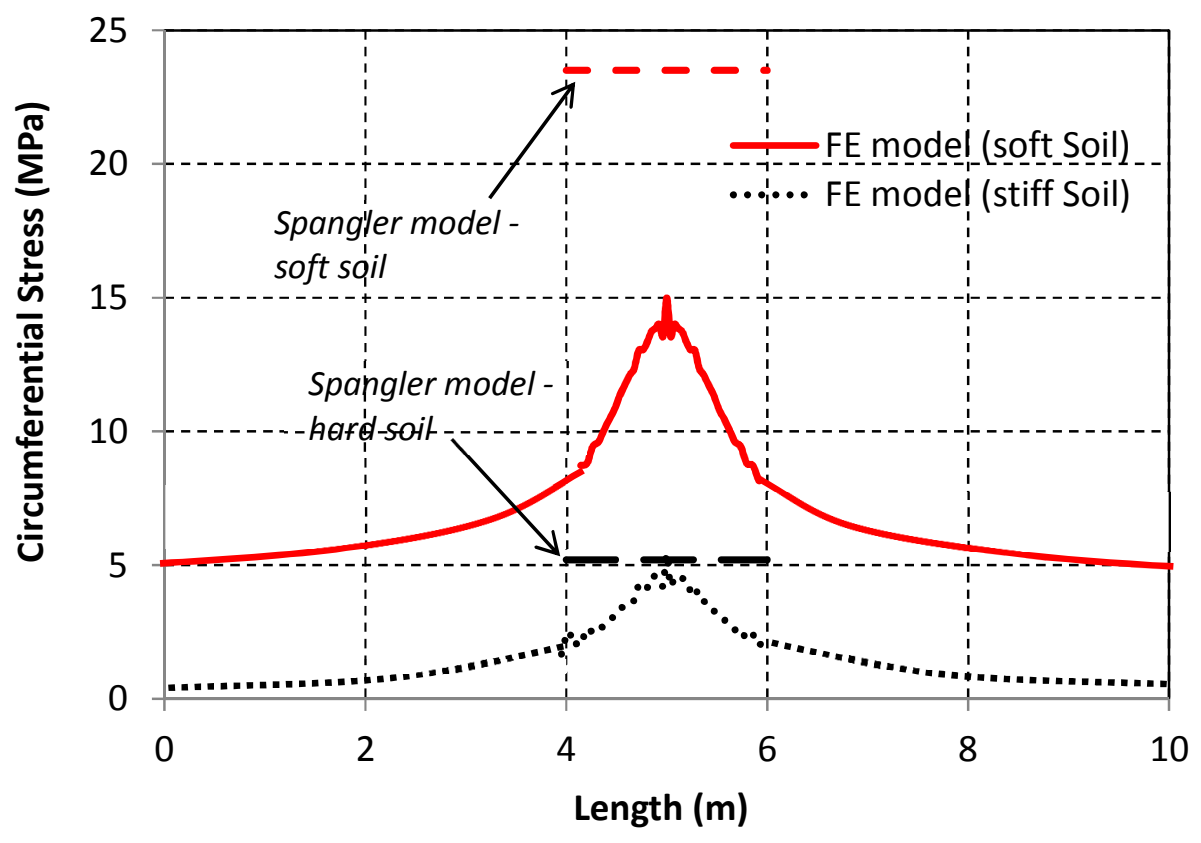

Figure 16 Pipe circumferential (hoop) stress plotted along the pipe length 


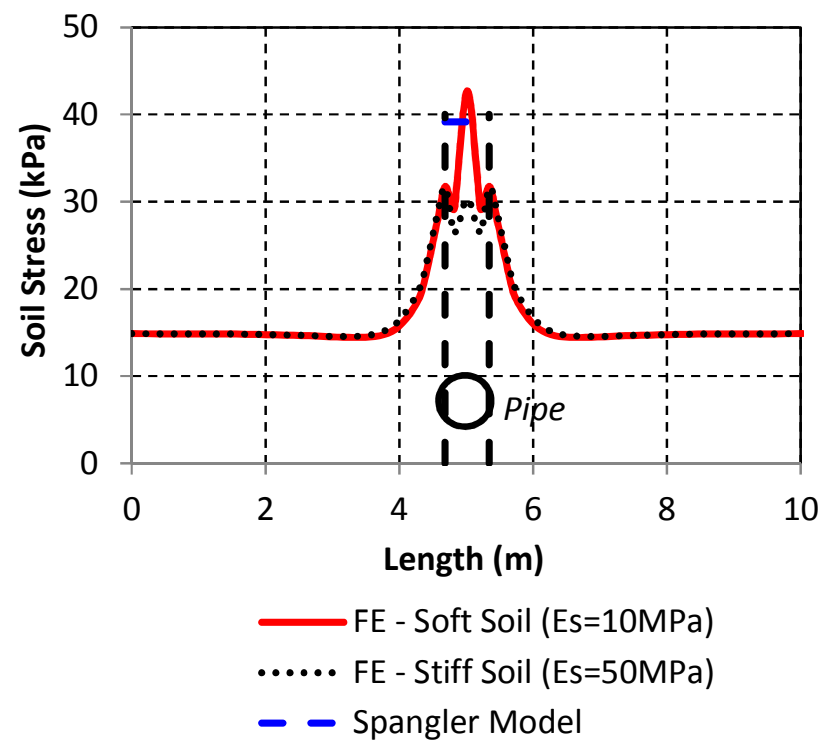

(a) Lateral direction

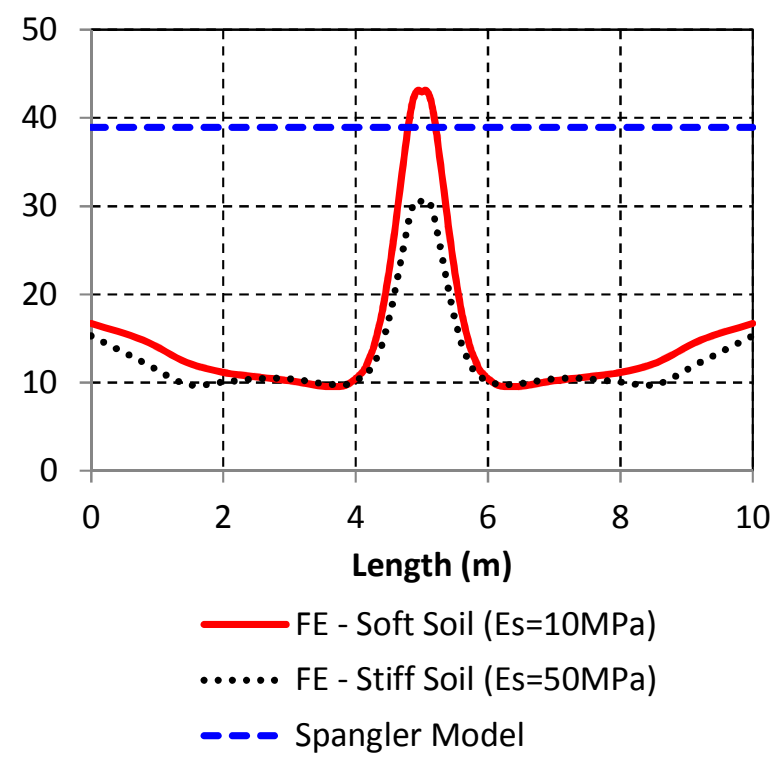

(b) Longitudinal direction

Figure 17 Vertical soil stresses plotted on top of the pipe (a) Lateral direction and (b) Longitudinal direction 


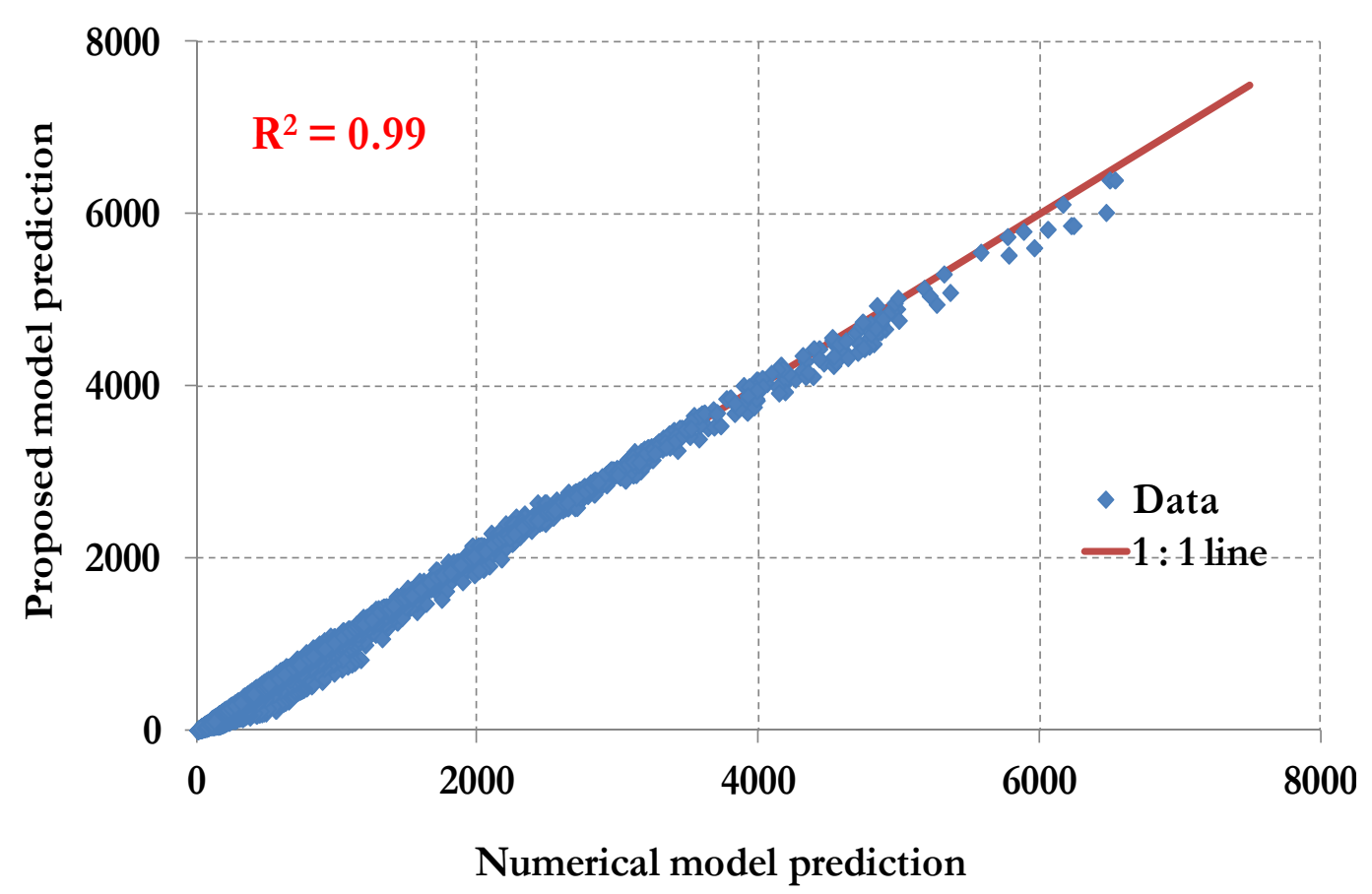

(a)

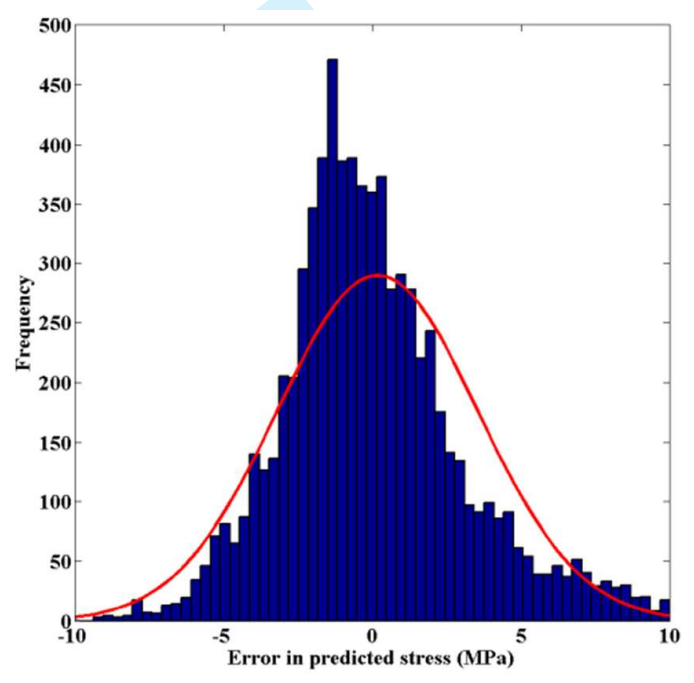

(b)

Figure 18 (a) Comparison of predictions from the numerical model and the proposed equation, (b) error in the prediction together with fitted normal distribution 


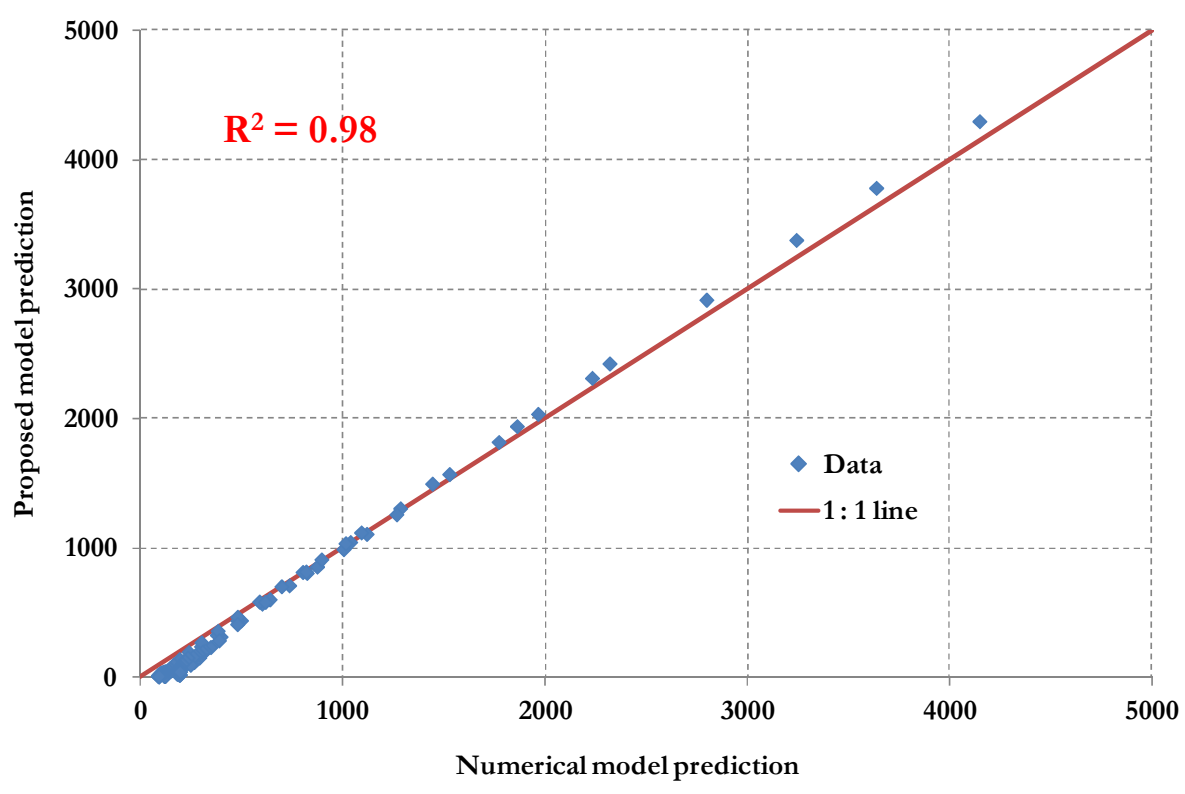

Figure 19. Comparison of proposed equation and numerical model prediction 


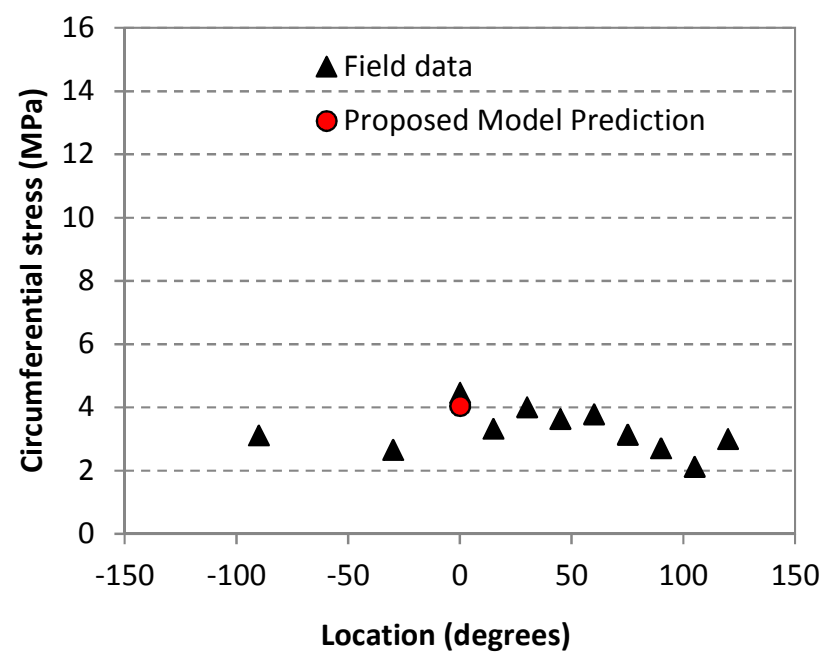

(a) $\mathrm{P}=200 \mathrm{kPa} \& \mathrm{~W}=0 \mathrm{kN}$

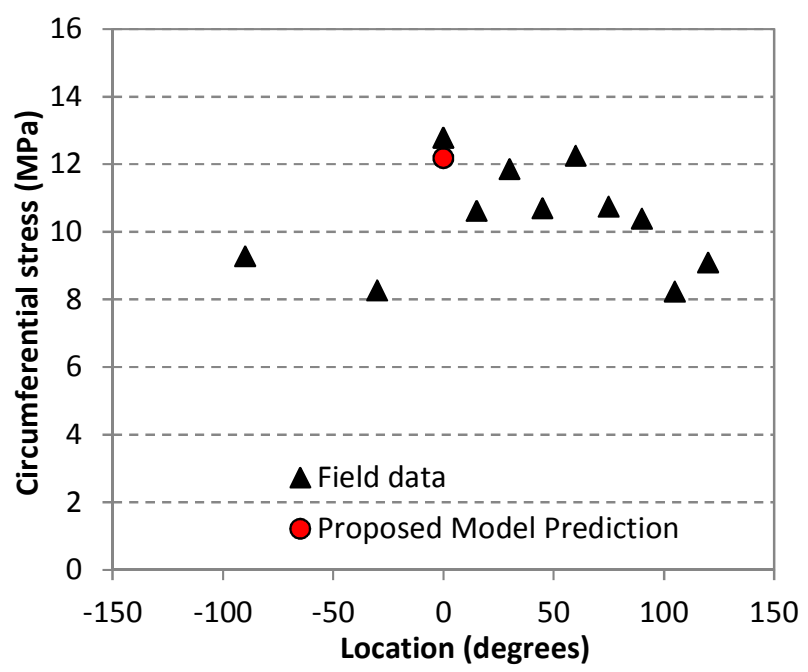

(c) $\mathrm{P}=690 \mathrm{kPa} \& \mathrm{~W}=0 \mathrm{kN}$

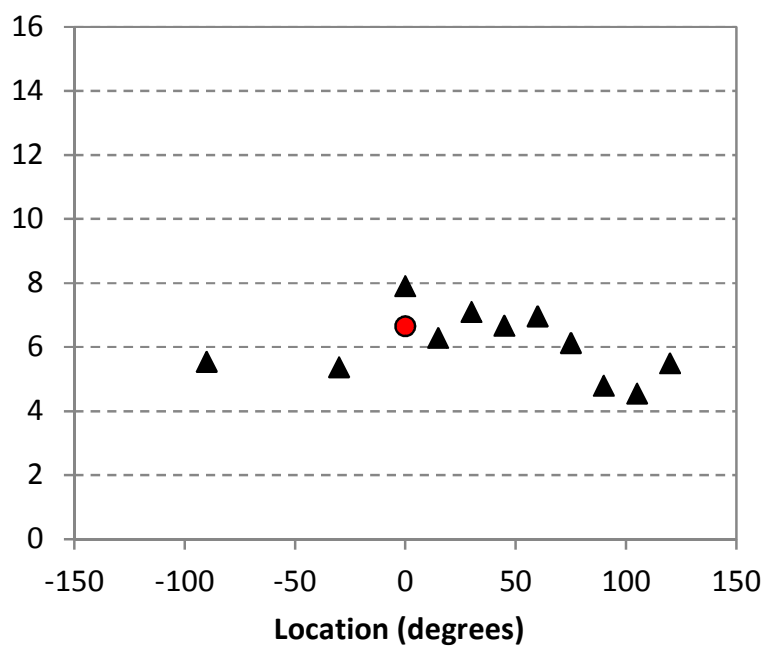

(b) $\mathrm{P}=350 \mathrm{kPa} \& \mathrm{~W}=0 \mathrm{kN}$

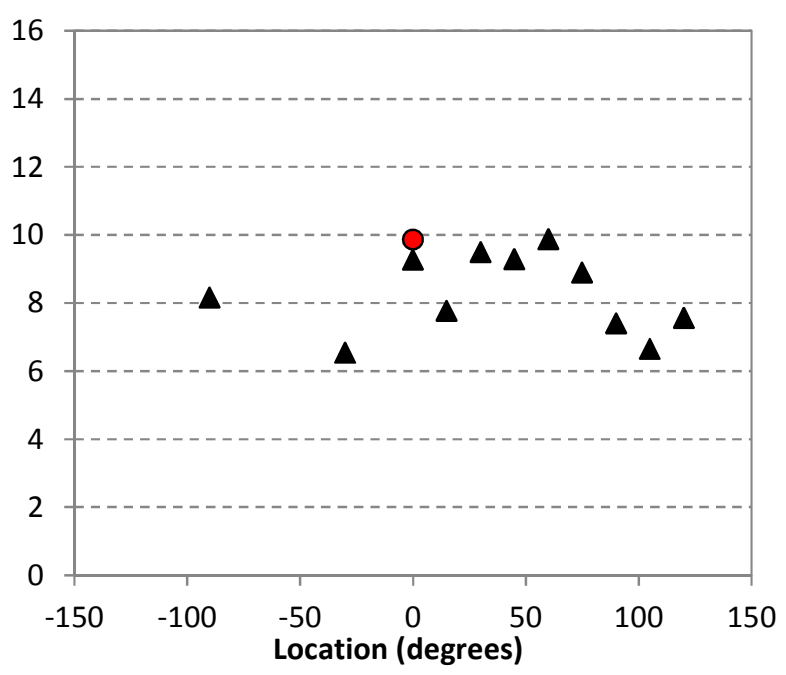

(d) $\mathrm{P}=523 \mathrm{kPa} \& \mathrm{~W}=30 \mathrm{kN}$

Figure 20. Comparison of proposed model outcomes with the field test data 


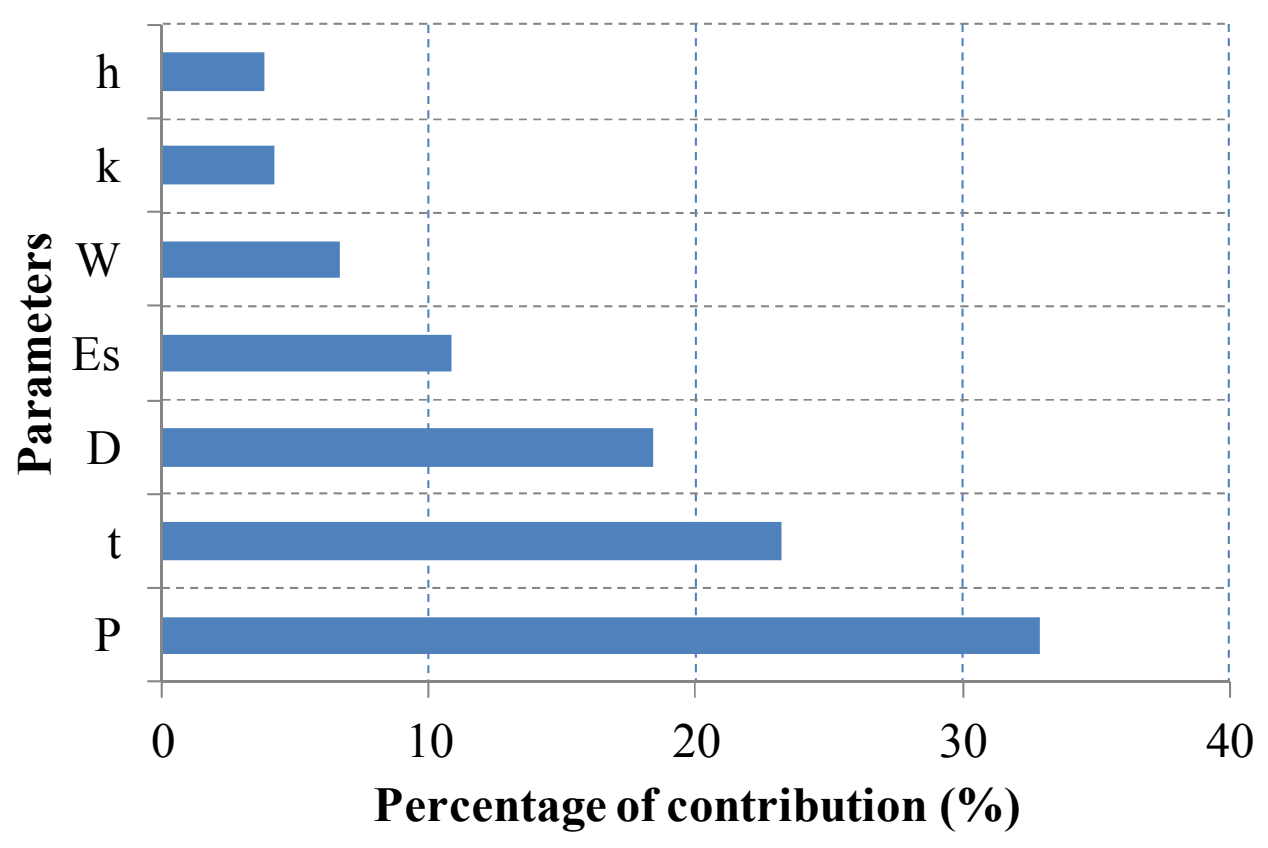

Figure 21 Results of the sensitivity analysis 


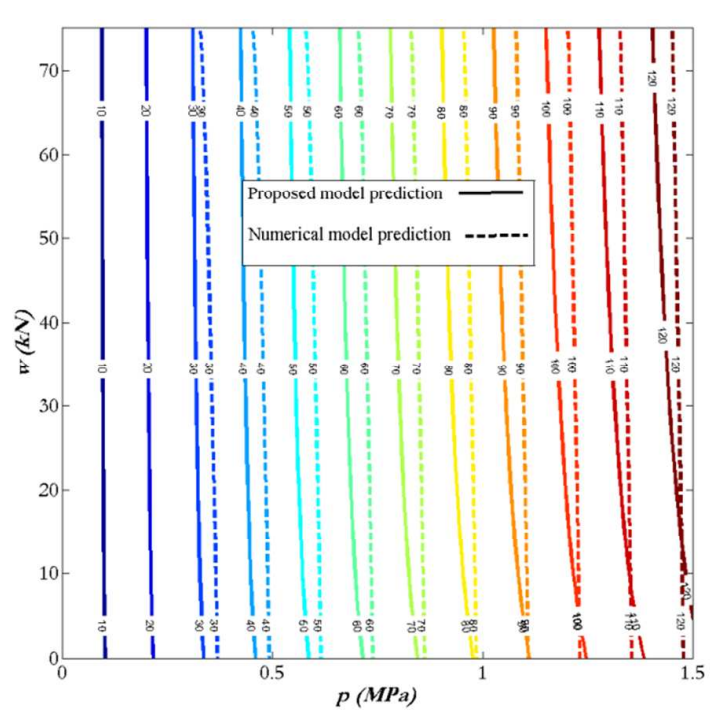

(a) $t=4 \mathrm{~mm}, D=660 \mathrm{~mm}, E_{s}=25000 \mathrm{kPa}$,

$$
h=1.3 \mathrm{~m}
$$

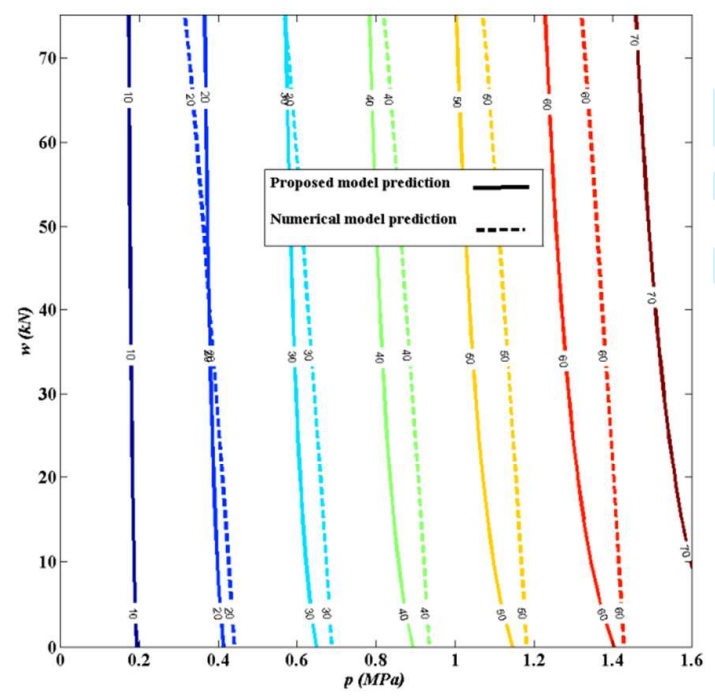

(c) $t=8 \mathrm{~mm}, D=660 \mathrm{~mm}, E_{s}=25000 \mathrm{kPa}, h=$

$$
1.3 \mathrm{~m}
$$

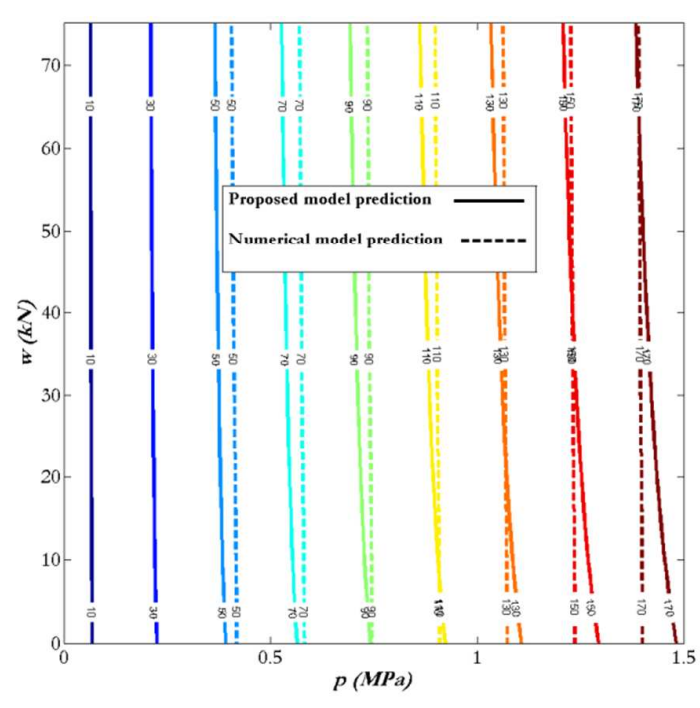

(b) $t=4 \mathrm{~mm}, D=1000 \mathrm{~mm}, E_{s}=25000$ $\mathrm{kPa}, h=0.8 \mathrm{~m}$

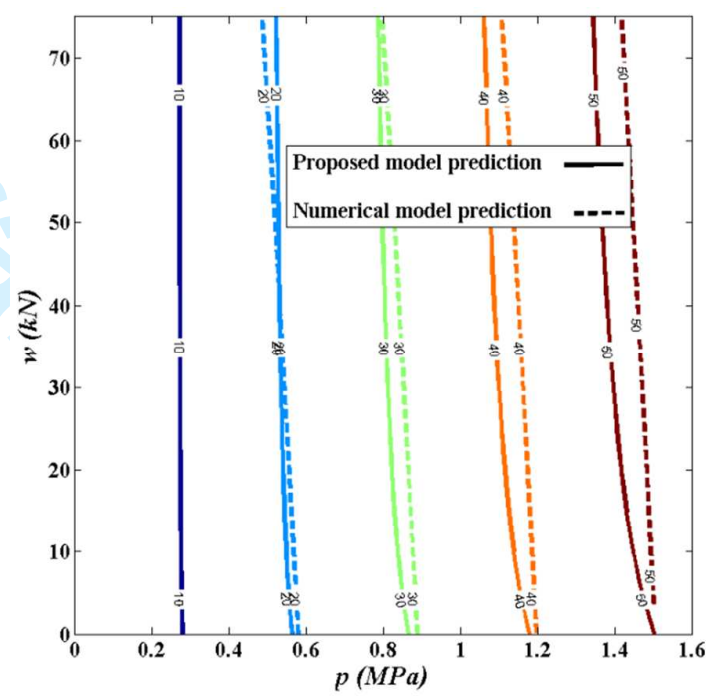

(d) $t=10 \mathrm{~mm}, D=660 \mathrm{~mm}, E_{s}=50000 \mathrm{kPa}, h=$ $1.3 \mathrm{~m}$

Figure 22. Comparison of predicted maximum stress using the proposed model and numerical model simulation for pipe subjected to traffic load and internal pressure $\left(k=0.4, E_{p}=100 \mathrm{GPa}, \gamma=19.13\right.$ $\left.\mathrm{kN} / \mathrm{m}^{3}\right)$ 


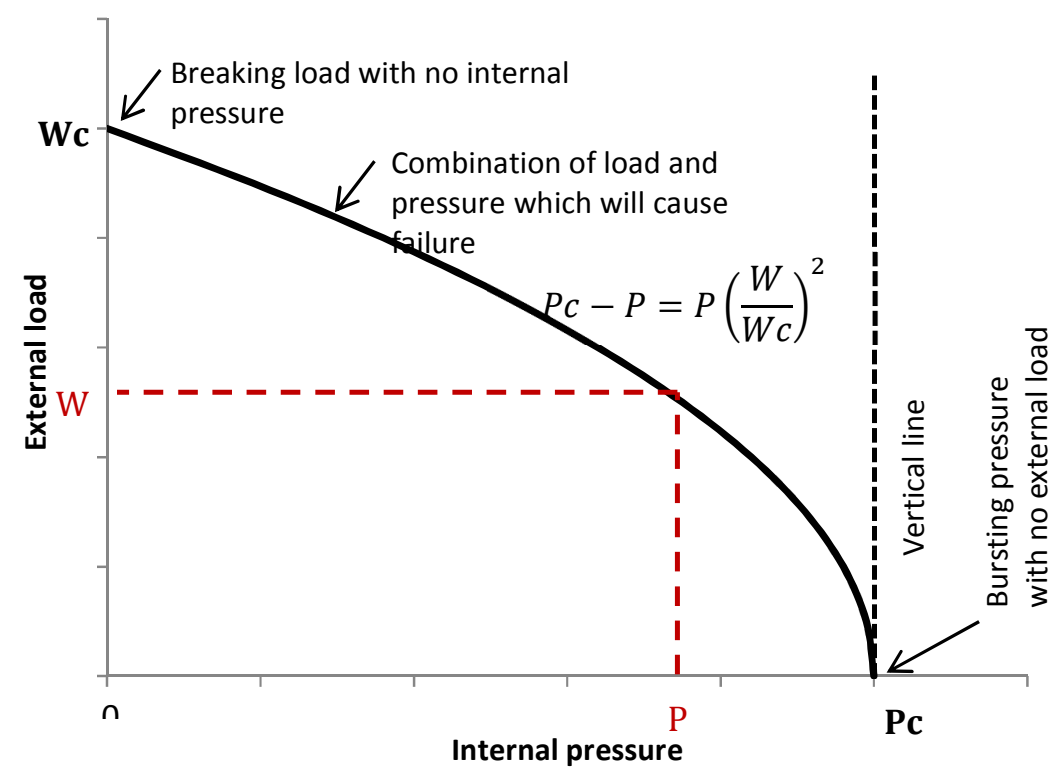

Figure 23 Schematic Schlick diagram

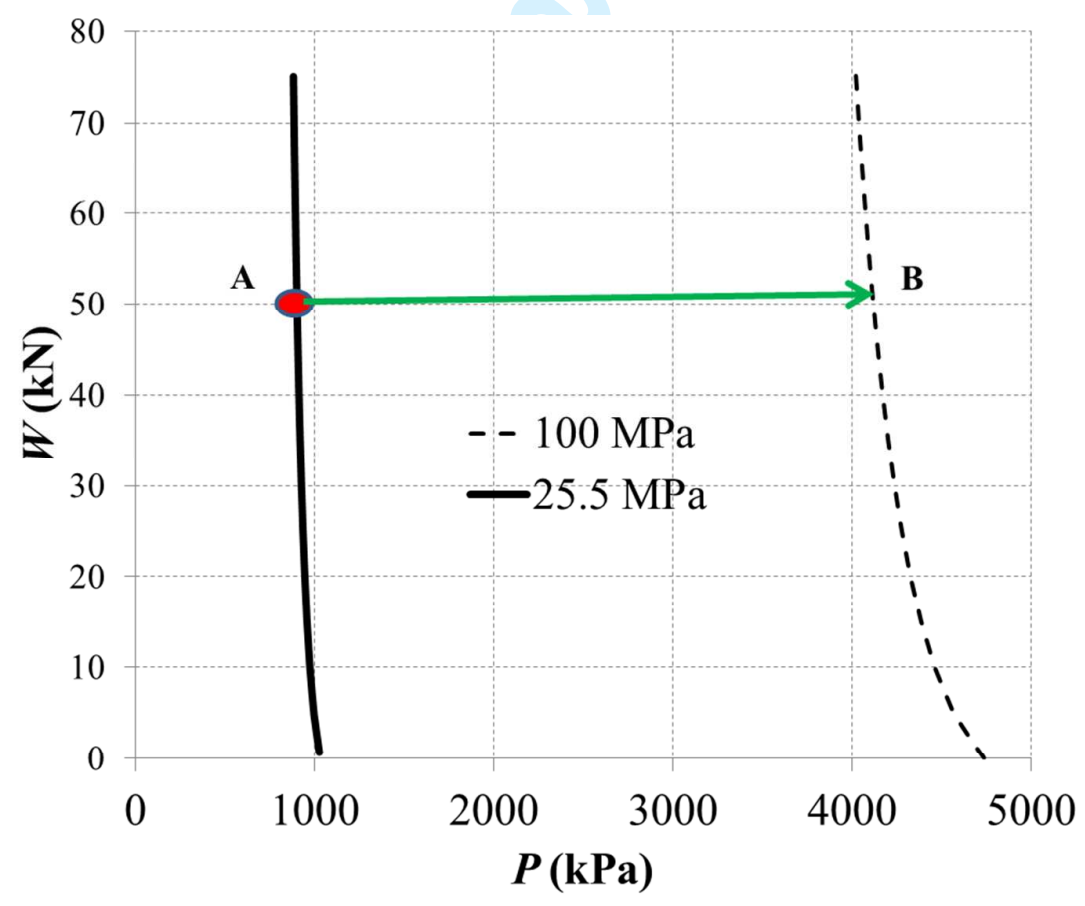

Figure 24 Load- pressure interaction diagram for example 1 
Table 1 Range of physical parameters and non-dimensionless variables

\begin{tabular}{|c|c|c|}
\hline Variable Description & Unit & Value \\
\hline$E_{s}$ & $\mathrm{MPa}$ & $2,4,10,25,50$ \\
\hline$E_{p}$ & $\mathrm{GPa}$ & 100 \\
\hline$v$ & - & 0.3 \\
\hline$D$ & $\mathrm{~mm}$ & $300,660,1000$ \\
\hline$t$ & $\mathrm{~mm}$ & $4,8,10,15,27$ \\
\hline$h$ & $\mathrm{~m}$ & $0.3,0.8,1.3,2.0$ \\
\hline$k$ & - & $0.1,0.25,0.4$ \\
\hline$P$ & $\mathrm{kPa}$ & $300,500,800,1000,1300$, \\
\hline$W$ & $\mathrm{kN}$ & 0 to 75 \\
\hline$E_{p} / E_{s}$ & - & 2000 to 50,000 \\
\hline$h / D$ & - & 0.3 to 6.67 \\
\hline$D / t$ & - & $\approx 11$ to 250 \\
\hline$P / E_{s}$ & - & 0 to 0.03 \\
\hline$E_{s} /(\gamma \cdot h)$ & & 53 to 8772 \\
\hline$W /\left(\gamma \cdot D^{2} \cdot h\right)$ & - & 0 to 146.2 \\
\hline & & \\
\hline
\end{tabular}

Table 2: Material properties used in the FE model

\begin{tabular}{|c|c|c|c|}
\hline \multirow{2}{*}{ Description } & \multicolumn{3}{|c|}{ Properties } \\
\cline { 2 - 4 } & Stiffness (MPa) & Poisson's ratio & Density $\left(\mathbf{k g} / \mathbf{m}^{3}\right)$ \\
\hline Pipe & 120000 & 0.3 & 7850 \\
\hline Asphalt & 175 & 0.3 & 2230 \\
\hline Base & 100 & 0.3 & 2000 \\
\hline Subgrade & 8 & 0.3 & 1850 \\
\hline
\end{tabular}


Table 3 Typical axle configurations and ranges of axle loads measured at a WIM system in Victoria (Austroads, 2010)

\begin{tabular}{|c|c|c|c|c|c|}
\hline $\begin{array}{c}\text { Axle configuration, } \\
\text { proportion of axles of } \\
\text { total }\end{array}$ & $\begin{array}{c}\text { Single axle } \\
\text { single tyres } \\
\text { (SAST), } \\
40 \%\end{array}$ & $\begin{array}{c}\text { Single axle } \\
\text { dual tyres } \\
\text { (SADT), } \\
21 \%\end{array}$ & $\begin{array}{c}\text { Tandam axle } \\
\text { single tyre } \\
\text { (TAST) } \\
2 \%\end{array}$ & $\begin{array}{c}\text { Tridam axle } \\
\text { dual tyres } \\
\text { (TRDT), } \\
12 \%\end{array}$ & $\begin{array}{c}\text { Tandem axle } \\
\text { dual tyres } \\
\text { (TADT) } \\
26 \%\end{array}$ \\
\hline $\begin{array}{c}\text { Load range whole axle, } \\
\qquad \mathrm{kN} \\
\text { (approx. per tyre, } \mathrm{kN} \text { ) }\end{array}$ & (5 to 70$)$ & (2.5 to 45$)$ & (2.5 to 50$)$ & (0.8 to 28$)$ & (1.25 to 40$)$ \\
\hline
\end{tabular}

Table 4 Comparison of maximum pipe tensile stresses between FE model and analytical models

\begin{tabular}{|c|c|c|c|c|c|c|}
\hline \multirow{3}{*}{ Case } & \multicolumn{6}{|c|}{ Maximum Pipe Tensile Stress (MPa) } \\
\hline & \multicolumn{2}{|c|}{ Ring Model $^{3}$} & \multicolumn{2}{|c|}{ Spangler Model } & \multicolumn{2}{|c|}{ FE Model } \\
\hline & Soil & Soil + Traffic & Soil & $\begin{array}{c}\text { Soil + } \\
\text { Traffic }\end{array}$ & Soil & $\begin{array}{c}\text { Soil }+ \\
\text { Traffic }\end{array}$ \\
\hline 1 & $38.2(2147 \%)^{4} / 23.2^{1}(1265 \%)^{4}$ & $76.5(1371 \%)^{4} / 45.4^{1}(773 \%)^{4}$ & $2.0(17 \%)^{4}$ & $5.2(0 \%)^{4}$ & 1.7 & 5.2 \\
\hline 2 & $38.2(620 \%)^{4} / 23.2^{1}(337 \%)^{4}$ & $76.5(410 \%)^{4} / 45.4^{1}(203 \%)^{4}$ & $9.0(70 \%)^{4}$ & $23.5(56 \%)^{4}$ & 5.3 & 15.0 \\
\hline 3 & $38.2(83 \%)^{4} / 23.2^{1}(11 \%)^{4}$ & $76.5(101 \%)^{4} / 45.4^{1}(19 \%)^{4}$ & $30.3(45 \%)^{4}$ & $78.4(106 \%)^{4}$ & $\begin{array}{l}16.0 / \\
20.8^{2}\end{array}$ & $30.0 / 38.0^{2}$ \\
\hline \multicolumn{7}{|c|}{ Note 1: Pipe stresses using modified Ring Model (Eq. 2) } \\
\hline \multicolumn{7}{|c|}{ Note 2: Pipe stresses for stiff pipe $(E=207 \mathrm{GPa})$} \\
\hline \multicolumn{7}{|c|}{ Note 3: $q$ for ring model was computed using Boussinesq's solution } \\
\hline
\end{tabular}


Table 5 Regressed model coefficients

\begin{tabular}{|c|c|c|c|c|c|c|c|}
\hline Parameter & $\alpha_{1}$ & $\alpha_{2}$ & $\alpha_{3}$ & $\alpha_{4}$ & $\alpha_{5}$ & $\alpha_{6}$ & $\alpha_{7}$ \\
\hline Value & 0.12 & 4.08 & $1.76 \mathrm{E}+06$ & $7.65 \mathrm{E}+04$ & $4.17 \mathrm{E}+06$ & $-3.23 \mathrm{E}+07$ & $-3.55 \mathrm{E}+07$ \\
\hline Parameter & $\beta_{1}$ & $\beta_{2}$ & $\beta_{3}$ & $\beta_{4}$ & $\beta_{5}$ & $\beta_{6}$ & $\beta_{7}$ \\
\hline Value & 0.086 & 0.94 & 0.89 & 0.88 & 0.94 & -0.51 & -0.71 \\
\hline
\end{tabular}

*The coefficients were estimated using the results from the numerical analyses performed for the range of parameters in Table 1. 